\title{
MODELING OF DARK FERMENTATION PROCESS FOR VOLATILE FATTY ACIDS PRODUCTION
}

\author{
By
}

Raman Sharma

B. TECH, Punjab Technical university, 2014

\author{
A Major Research Project \\ presented to Ryerson University \\ in partial fulfillment of the \\ requirements for the degree of \\ Master of Engineering \\ in the program of \\ Civil Engineering
}

Toronto, Ontario, Canada, 2018

(C) Raman Sharma,2018 


\section{Author's Declaration}

I hereby declare that I am the sole author of this MRP. This is a true copy of the MRP, including any required final revisions.

I authorize Ryerson University to lend this MRP to other institutions or individuals for scholarly research.

I further authorize Ryerson University to reproduce this MRP by photocopying or by other means, in total or in part, at the request of other institutions or individuals for scholarly research.

I understand that my MRP may be made electronically available to the public. 


\section{Abstract}

Modeling of Volatile fatty acids under anaerobic condition dark fermentation process

$$
\begin{gathered}
\text { Master of Engineering,2018 } \\
\text { Raman Sharma } \\
\text { Civil Engineering } \\
\text { Ryerson University }
\end{gathered}
$$

This study examined the fermentation process for the production of volatile fatty acids from the organic waste. The depletion of fossil fuels motivated researchers to search for alternative energy and fuels instead of relying on the non-renewable way of energy and fuel production. Anaerobic digestion is a biochemical process in the absence of oxygen, where complex organic matter are degraded. The different stages of anaerobic digestion and important operating parameters such as $\mathrm{pH}$, temperature and retention time. The most suitable feedstock and its effects on the treatment process are discussed.

This study evaluates the modelling of VFAs production. The paper also demonstrates various model like ADM1, surface limiting model, and steady-state model. Furthermore, an experimental setup consisting of two semi-continuous reactors was employed for the sample analysis. The reactors were fed with raw and pre-treated source separated organics with solid retention time of 3 days.

Keywords: Anaerobic digestion, Feedstocks, SSO, VFAs, ADM1. 


\section{Acknowledgments}

I would like to thank Dr. Elsayed Elbeshbishy for his patient guidance, support and advice throughout this project. His expertise was the key to understanding and overcoming many of the difficulties I encountered during my research.

I would also like to extend my gratitude to Dr. Ehssan Hosseini Koupaie and Dr. Amir Abbas Bazyar Laheh for providing timely and accurate knowledge that was paramount to the experimental work of this research.

I am grateful to Armineh Azizi and Farokh Laqa Kakar, for the invaluable help with my training and experimental set up and their insights for the analytical methods used in this study.

Finally, to my family and friends, thank you for sharing this journey with me. You are the source of all inspiration. 


\section{$\underline{\text { Table of Contents }}$}

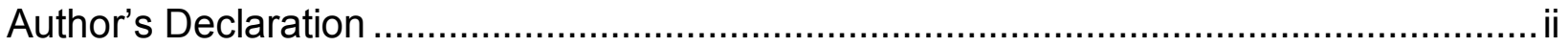

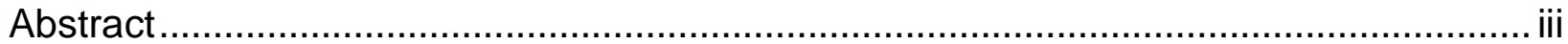

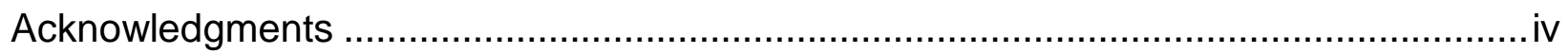

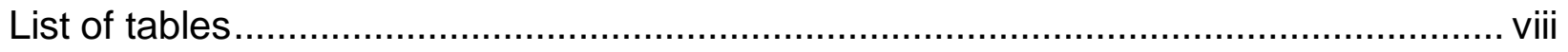

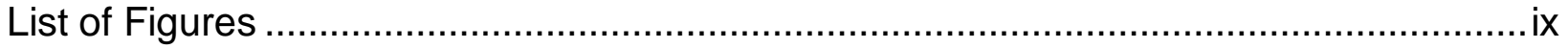

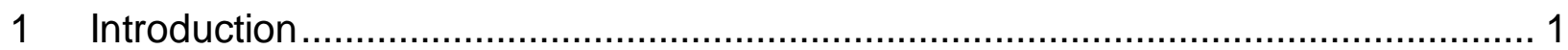

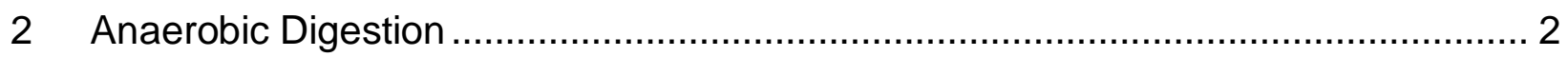

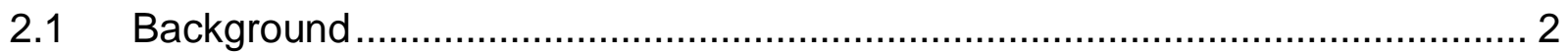

2.2 What Is Anaerobic Digestion? .............................................................. 2

3 Anaerobic Digestion Process......................................................................... 3

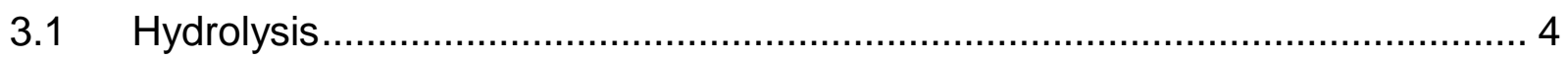

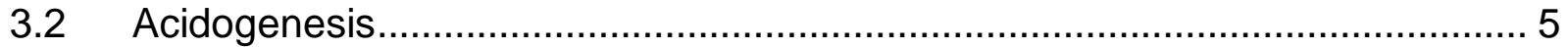

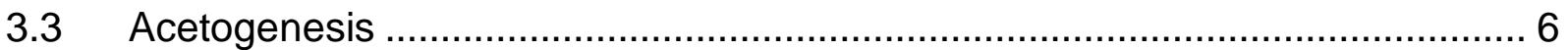

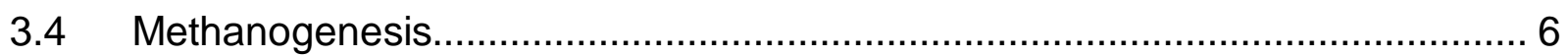

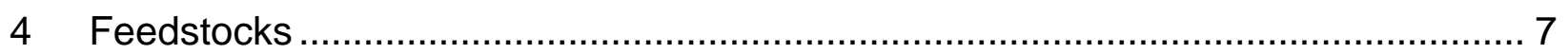

4.1 Industrial waste and wastewater …………............................................. 7

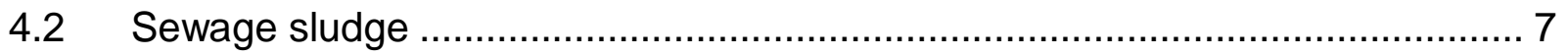

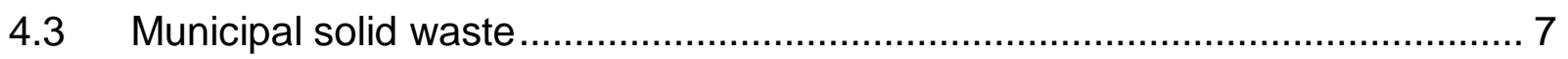

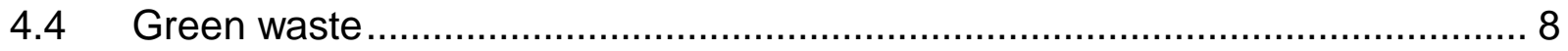

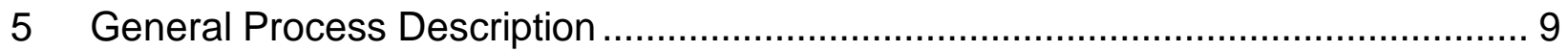

6 Environmental Factors \& Operational Parameters Influencing AD ........................ 10

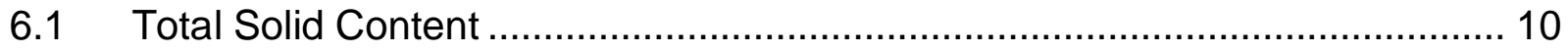


6.2 Organic Loading Rate ........................................................................... 11

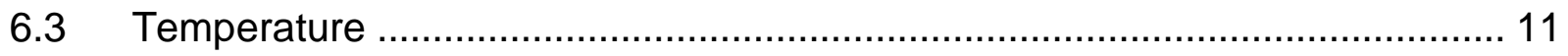

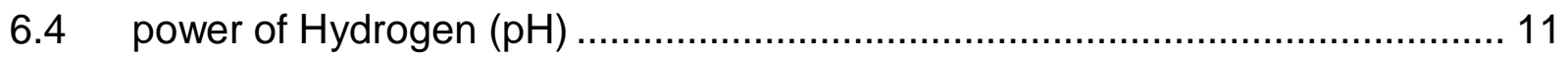

6.5 Hydraulic Retention Time ...................................................................... 12

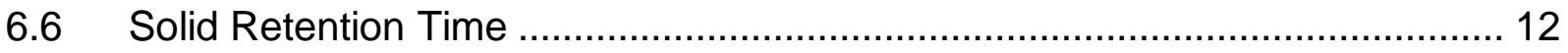

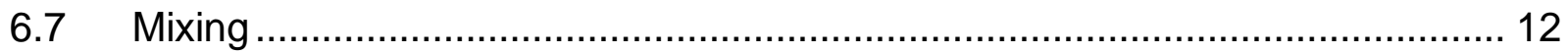

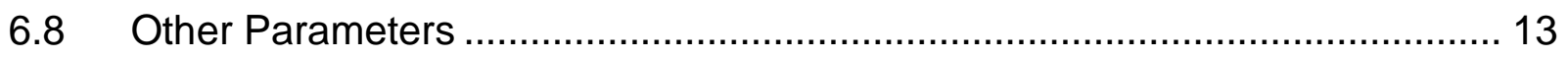

$7 \quad$ Literature Review for Volatile Fatty Acid Models ................................................. 14

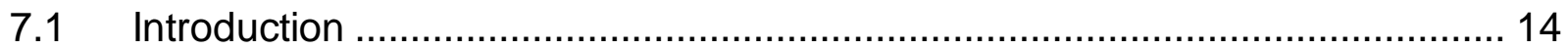

8 Models for VFA Production ........................................................................... 15

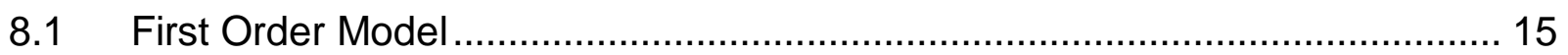

8.2 Steady State Acid Fermentation Model .................................................. 15

8.3 Anaerobic Digestion Model No 1 …….................................................... 16

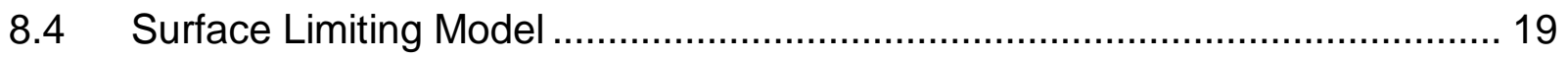

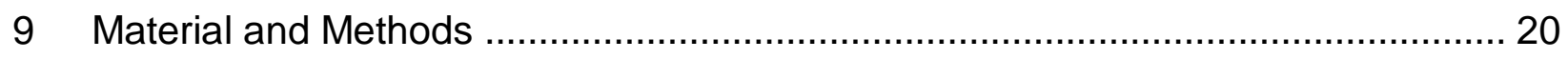

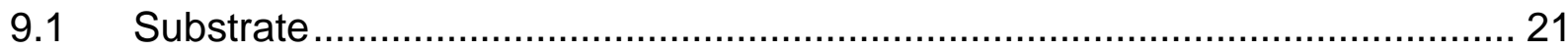

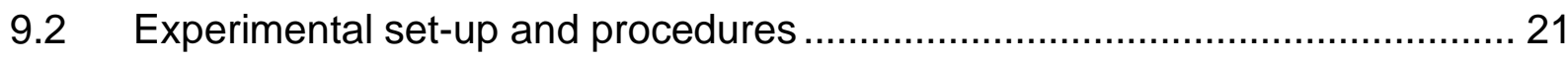

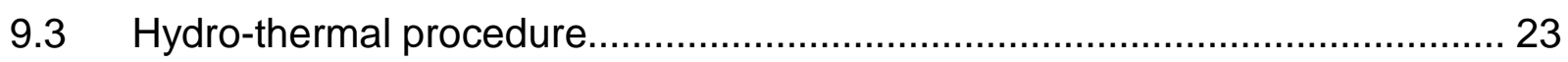

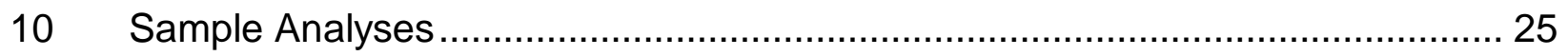

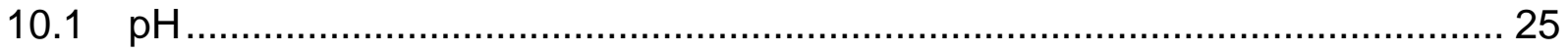

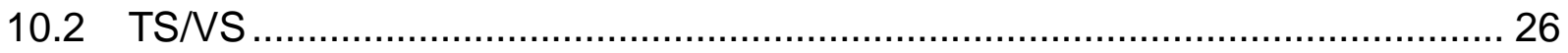

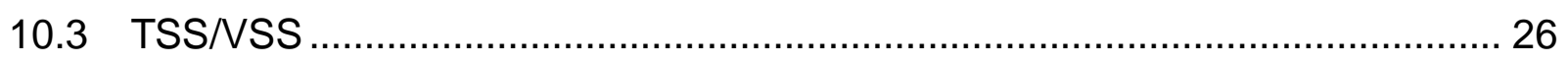

10.4 Chemical Oxygen Demand (Total / Soluble) ................................................. 26

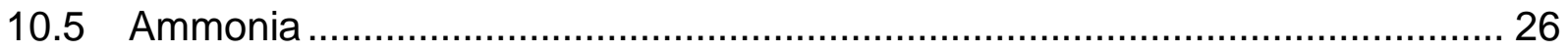




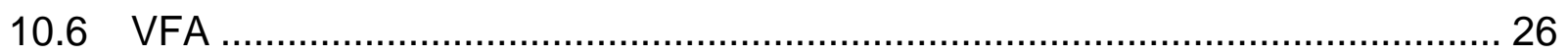

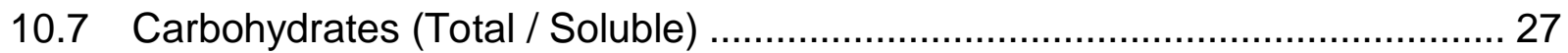

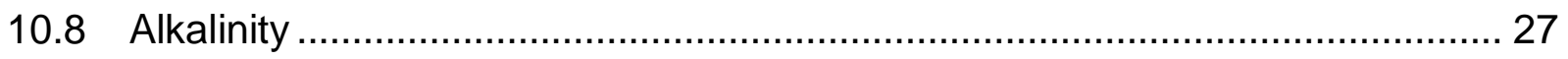

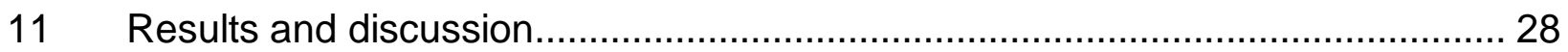

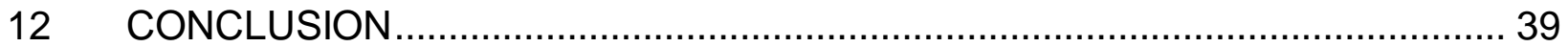

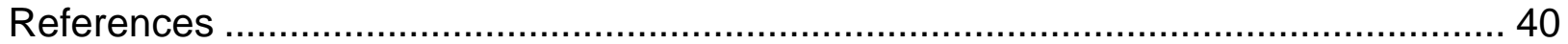

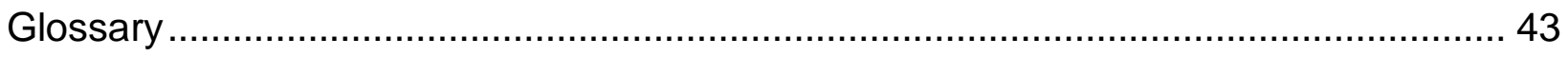




\section{List of tables}

Table 1: Average properties of feed source separated organics ................................ 20

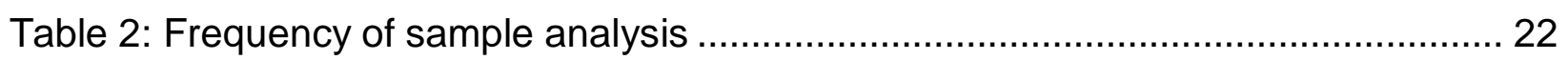




\section{List of Figures}

Figure 1: Anaerobic digester configuration source (Neibling, June 2014)...................... 3

Figure 2: Four steps for anaerobic digestion source (Chen, June 2014) ....................... 4

Figure 3: Several feedstocks for treatment source (Steffen \& Szolar, 1998) .................. 8

Figure 4: General process for anaerobic digestion plan Source (Monnet, 2003) .......... 10

Figure 5 : Operational parameters for anaerobic digestion Source (Yang, 15 December

2015) 13

Figure 6: Experimental anaerobic digester setup. Raw (left) \& pretreated (right) SSO. 21

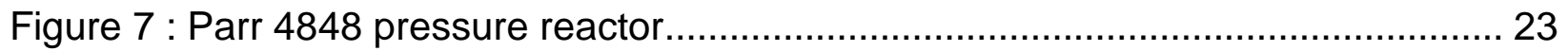

Figure 8: Temperature pattern for hydro-thermal .................................................. 24

Figure 9: Parr 4848 controller showing temperature graph ........................................ 24

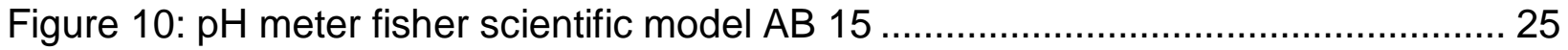

Figure 11: Thermo fisher scientific centrifuge machine........................................... 27

Figure 12 : Total \& volatile solid of raw \& pre-treated SSO ...................................... 28

Figure 13: Total \& volatile suspended solid of raw \& pre-treated SSO ......................... 29

Figure 14: Total chemical oxygen demand of raw \& pre-treated SSO .......................... 30

Figure 15: Soluble chemical oxygen demand of raw \& pretreated SSO ....................... 31

Figure 16: Total carbohydrates of raw \& pre-treated SSO......................................... 32

Figure 17: Soluble carbohydrates of raw \& pre-treated SSO ….................................. 33

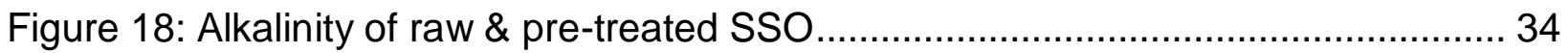


Figure 19: Ammonia of raw \& pre-treated SSO....................................................... 35

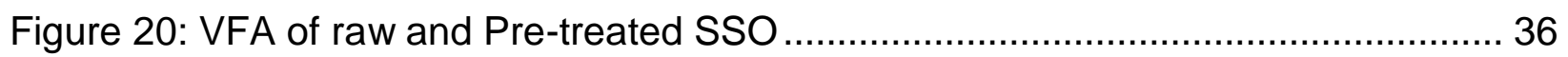

Figure 21: Degree of solubilization of SSO versus Percentage ................................... 37

Figure 22: Fermentation process versus percentage of suspended solid reduction...... 38 


\section{Introduction}

In the modern era, one of the biotechnologies developed is to utilize the waste for useful energy and material recovery using anaerobic digestion. Municipal waste contributes to environmental problems including habitat destruction, surface and groundwater pollution and increased emission of greenhouse gases and the impact on climate change. In 2008, Canadian household generated $777 \mathrm{~kg}$ per capita annually municipal waste which was twice as much as Japan. In the same year, 8.5 million tons of waste out of 13 million were disposed of in landfills. Landfills are the most common in Canada, but there is environmental concern about landfills like leachate and gases that contaminate groundwater and surface water (R. Hester, 2002). To achieve more sustainable municipal waste, the treatment of this waste is an essential concern for solid waste management and to reduce the toxicity and volume of waste disposal in landfills. The anaerobic digestion technology is one of the leading options for processing the organic material in municipal solid waste (Verma, 2002).

The most prominent method for production of methane gas from organic matter is high rate anaerobic digesters. Anaerobic digestion has become the main biological process to treat the organic matter. In the end stage of the process, the end products are methane gas, carbon dioxide and highly nutritive digestate which can be further used as fertilizers for the soil. Anaerobic digestion is a most efficient process to treat and utilize food waste for energy recycling (Muzaffar Ahmad Mir, February 2016). Also, anaerobic digestion is used to obtain volatile fatty acids in metabolic intermediates in the acidification step of the AD process. (Tânia Gameiro, September 2016)

Fermentation technology is receiving revived recognition as a sustainable and economically technology to produce a variety of energy through the process such as methane, ethanol, butanol, and hydrogen from a waste material through anaerobic digestion which is inexpensive and renewable (Silva, 2014). Anaerobic fermentation is an effective bioprocess for the production of volatile fatty acids and another organic compound such as alcohol. Also, anaerobic fermentation of organic waste with high hydrolysis rate can process for biogas production. The VFA production and other 
composed mixture by hydrolytic - acidogenic fermentation of organic waste have a significant influence on the performance of the process and other applications.

\section{Anaerobic Digestion}

\subsection{Background}

Anaerobic biological treatment is well understood and used frequently as anaerobic digesters to treat complex organic solid waste. Anaerobic digestion treatment has been one of the effective treatment options for biodegradable organic waste including food waste, animal manure, and sewage sludge as it effectively reduces the amount of organic waste and produces biogas as renewable energy (Dong-Jin Lee, 2015). In the past, aerobic treatment was preferred, i.e. in the presence of oxygen in the treatment of wastewater as it was easy to operate. In comparison, anaerobic reactors were assumed to be less stable and more expensive to install, but this belief was due to the limited knowledge of the process and reactor design.

The application of anaerobic treatment has gradually increased in the past three decades. Due to the significant advantages of aerobic treatment, anaerobic treatment has emerged as a practical and economical process for the solid waste.

\subsection{What Is Anaerobic Digestion?}

Anaerobic digestion is the biological process that breaks down organic material in the absence of oxygen into methane and carbon dioxide. Organic materials are composed of organic compounds resulting from decomposition of previously living organisms such as plants and animal and their waste products. In figure 1 configuration of the anaerobic digester is illustrated. There are several different sources of organic material for anaerobic digestion such as municipal wastewater, food waste, and fats, etc. The end product of anaerobic digestion is biogas which is mainly composed of methane nearly about $60-70 \%$ by volume and carbon dioxide about $30-40 \%$ by volume along with some amount of 


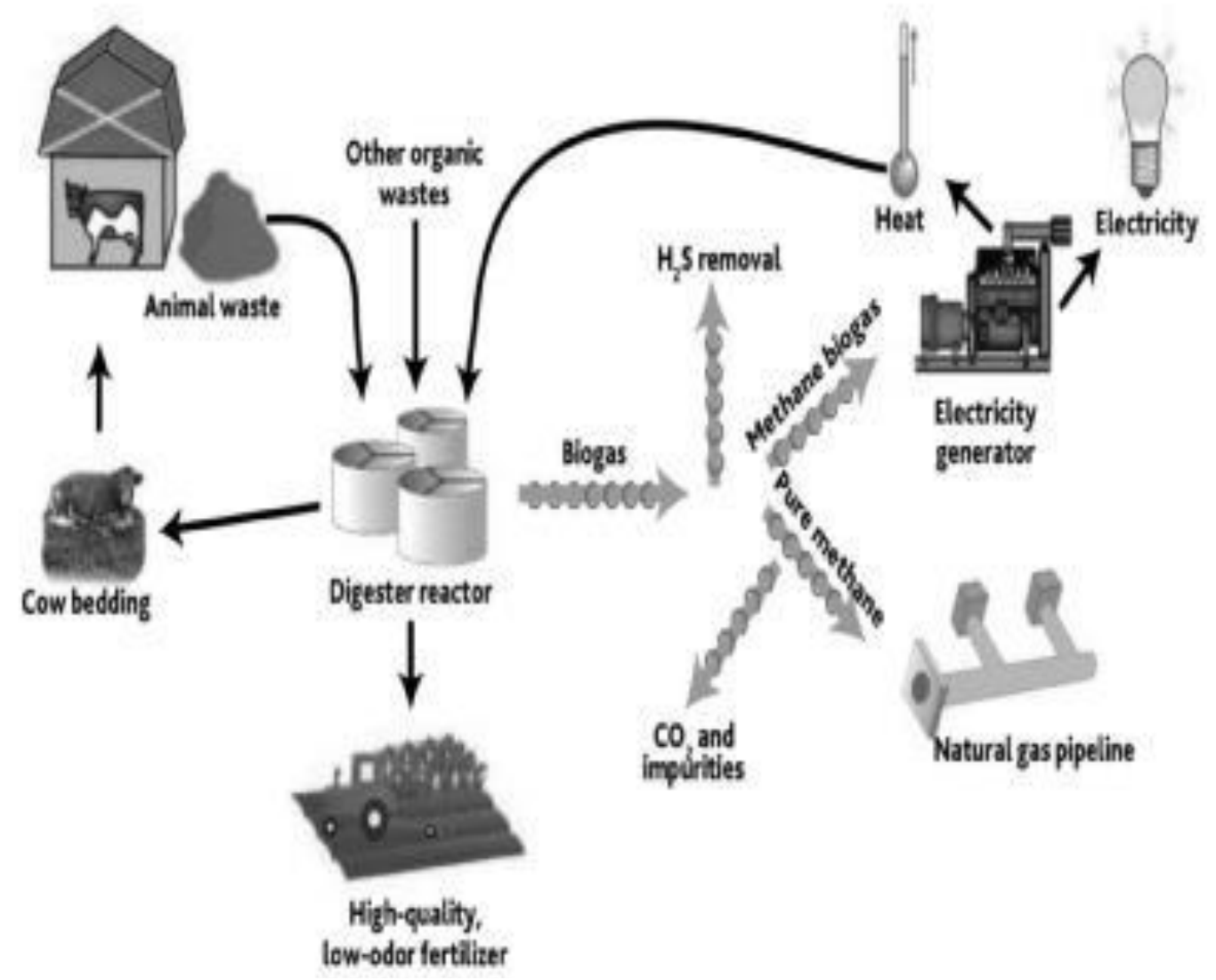

Figure 1: Anaerobic digester configuration source (Neibling, June 2014)

hydrogen sulphide and trace Gases. Biogas can be used for heat production, generate electricity and renewable natural gas. (Chen, June 2014)

Digested solid left over after the treatment can be composted and utilized as agricultural fertilizers as it is rich in nutrients. The AD is carried out at different temperature conditions, such as mesophilic and thermophilic, and various other factors which can alter the process in numerous ways is described briefly later (Muzaffar Ahmad Mir, February 2016).

\section{Anaerobic Digestion Process.}

Anaerobic biodegradation of organic material proceeds in the absence of oxygen and presence of the anaerobic microorganism. The various factor that depends on the removal efficiency of the organic matter such as nature and composition of organic matter 
depends on wastewater characterization, whereas sludge retention time and loading rate depend on the design of treatment system. Figure 2 shows the four steps for anaerobic digestion and their products for each phase. Anaerobic digestion (AD) occurs in four different phases namely:

I. Hydrolysis

II. Acidogenesis

III. Acetogenesis and

IV. Methanogenesis.

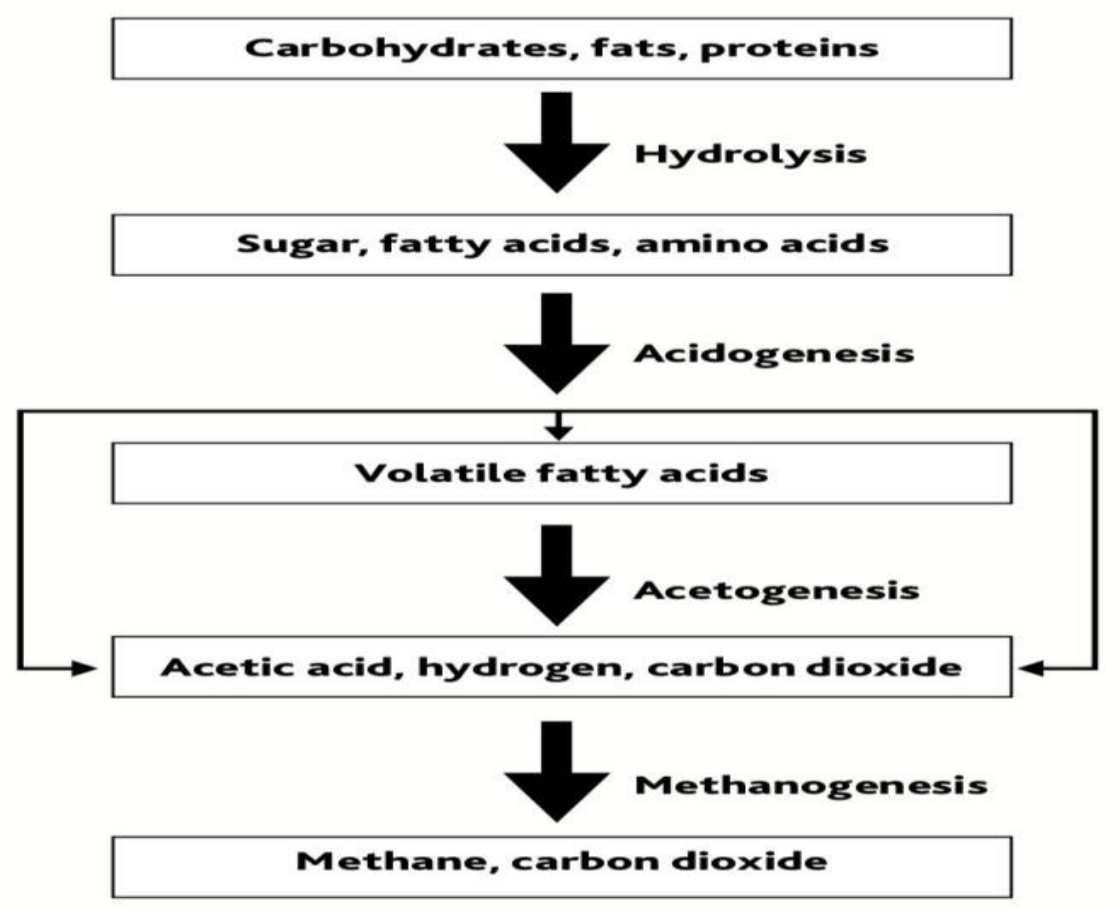

Figure 2: Four steps for anaerobic digestion source (Chen, June 2014)

\subsection{Hydrolysis}

In the first stage of $A D$ process, fermentative bacteria convert the insoluble complex organic matter into soluble organic matter such as cellulose into sugar, amino acid, and fatty acids, i.e., to compounds suitable for use as a source of energy. This step is carried 
out by strict anaerobes such as bactericides, clostridia, and facultative bacteria. The flowing equation represents the overall reaction:

$$
\mathrm{C}_{6} \mathrm{H}_{10} \mathrm{O}_{4} \longrightarrow \mathrm{C}_{6} \mathrm{H}_{12} \mathrm{O}_{6}+\mathrm{H}_{2} \mathrm{O}
$$

The first phase is critical due to the large organic molecules which are too large to be directly absorbed and used by microorganism as a food source. To accomplish biodegradation, specific microorganism produces different types of enzymes which break down the large molecules into the smaller pieces that the microorganism can be absorbed and use as a source of energy. Some microorganism emits several different enzymes, which allow them to break down different types of organic materials. A microorganism that breaks down into different sugars is called saccharolytic, while those that break down proteins are called proteolytic. The rate of decomposition during the hydrolysis state depend significantly upon the nature of the substrate (Kayode Feyisetan Adekunle, 2015).

\subsection{Acidogenesis}

The second stage is Acidogenesis, the reason to call this is because of the fermentative process, the dissolved organic compound in the form of amino acids and sugars will be converting into the volatile fatty acids, alcohols, lactic acid and mineral compounds like hydrogen sulfite, ammonia, carbon dioxide, etc. The $\mathrm{pH}$ of the system will be coming down at this stage because a lot of different types of organic acids will be generated in the process for example if the partial pressure of the hydrogen is high, it would decrease the number of reduced compounds. The flowing equations represent the overall reaction:

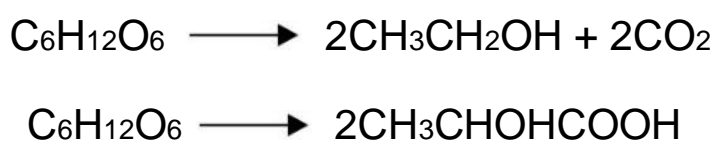

In this study, I will emphasize more on the production of volatile fatty acids in dark fermentation process, but it is important to study the whole process taking place to know its end products for various other uses. 


\subsection{Acetogenesis}

In the third stage, the product produced in the second phase is consumed by the substrate for the other microorganism. The product produced after the fermentation process are long chain fatty acids, so these long fatty acids cannot be converted directly to methane, so methanogenic bacteria are converted into the methanogenic substrate, volatile fatty acids, and alcohols. Further volatile fatty acids are oxidized into methanogenic substrates like acetic acid, hydrogen and carbon dioxide. Volatile fatty acids with longer carbon chain are oxidized into acetate and hydrogen. Oxidation reaction will only occur if the partial pressure of hydrogen is low, which explain the collaboration of methanogens is important so that hydrogen is continuously consumed to produce methane (Kayode Feyisetan Adekunle, 2015). Acetogenesis reaction is shown below:

$$
\begin{aligned}
\mathrm{CH}_{3} \mathrm{CH}_{2} \mathrm{COOH}+2 \mathrm{H}_{2} \mathrm{O} & \longrightarrow \mathrm{CH}_{3} \mathrm{COOH}+\mathrm{CO}_{2}+3 \mathrm{H}_{2} \\
\mathrm{CH}_{3} \mathrm{CH}_{2} \mathrm{CH}_{2} \mathrm{COOH}+2 \mathrm{H} & \longrightarrow 2 \mathrm{CH}_{3} \mathrm{COOH}+2 \mathrm{H}_{2} \\
\mathrm{CH}_{3} \mathrm{CH}_{2} \mathrm{OH} & \longrightarrow \mathrm{CH}_{3} \mathrm{COOH}+2 \mathrm{H}_{2}
\end{aligned}
$$

\subsection{Methanogenesis}

This stage is most critical and slowest biochemical reaction of the process. Methaneproducing bacteria are strict anaerobes and are vulnerable to even small amounts of oxygen. Methane production is higher is from the reduction of carbon dioxide with hydrogen.

$$
\begin{aligned}
& \mathrm{CH}_{3} \mathrm{COOH} \longrightarrow \mathrm{CH}_{4}+\mathrm{CO}_{2} \\
& 2 \mathrm{C}_{2} \mathrm{H}_{5} \mathrm{OH}+\mathrm{CO}_{2} \longrightarrow \mathrm{CH}_{4}+2 \mathrm{CH}_{3} \mathrm{COOH} \\
& \mathrm{CO}_{2}+4 \mathrm{H}_{2} \longrightarrow \mathrm{CH}_{4}+2 \mathrm{H}_{2} \mathrm{O}
\end{aligned}
$$




\section{Feedstocks}

Several feedstocks exist for the anaerobic digestion process, most of which comprise of organic matter and is suitable for treating anaerobic digestion which includes municipal solid waste, sewage sludge, green waste and organic industrial and commercial wastes. Feedstock characteristics are important factors affecting biogas production during anaerobic digestion. The primary feedstock characteristics comprise of moisture content, total solids, volatile solids, BOD, COD, carbon, and nitrogen. High concentration of VFAs and ammonia $\left(\mathrm{NH}_{3}\right)$ can cause toxicity and failure. Figure 3 dramatize several feedstocks for the treatment, and its description is described below.

\subsection{Industrial waste and wastewater}

Organic industrial and waste include a wide range of waste material from industrial and commercial operating which may form the suitable feedstock for the AD. Waste in high moisture content is suitable for the AD. AD for industrial wastewater is increasing rapidly as it is suitable for wastewater with COD content up to $50,000 \mathrm{mg} / \mathrm{L}$ and no oxygen supply are required for the treatment (Monnet, 2003).

\subsection{Sewage sludge}

Sewage sludge is highly active material produced for the biological treatment plant which starts fermentation on anaerobic condition. Sewage sludge is usually in liquid form with approximately $5 \%$ total solids (TS) (Monnet, 2003). Sewage sludge is a well-established technology as it is suitable to improve the dewatering capability and to obtain energy at low operational cost. In the digestion plant, the addition of sludge waste with MSW will increase the nutrient level as well as moisture content.

\subsection{Municipal solid waste}

The anaerobic digestion of municipal solid waste is entirely feasible. The fundamental issue in this is only that organic waste should be collected separately or has to be 
removed mechanically. The high quality product can be achieved if the process is well designed and run (Monnet, 2003). The main disadvantage is the source separation which involves new containers and vehicles for the collection which may result in higher cost. Also, it depends upon the purpose of the plant, if the purpose is to maximize the production of methane then the mixed collection is suitable.

\subsection{Green waste}

Green waste is garden and parks waste. These wastes need to be shredded to give more homogenous feedstock. It may contain woody lignin which is not biodegradable. Lignin roughly constitutes around $30 \%$ wood, and its biodegradability can be increased through some physical and chemical processes, but such processes were only used when plant materials are to be degraded anaerobically else it will increase the treatment cost (Monnet, 2003).

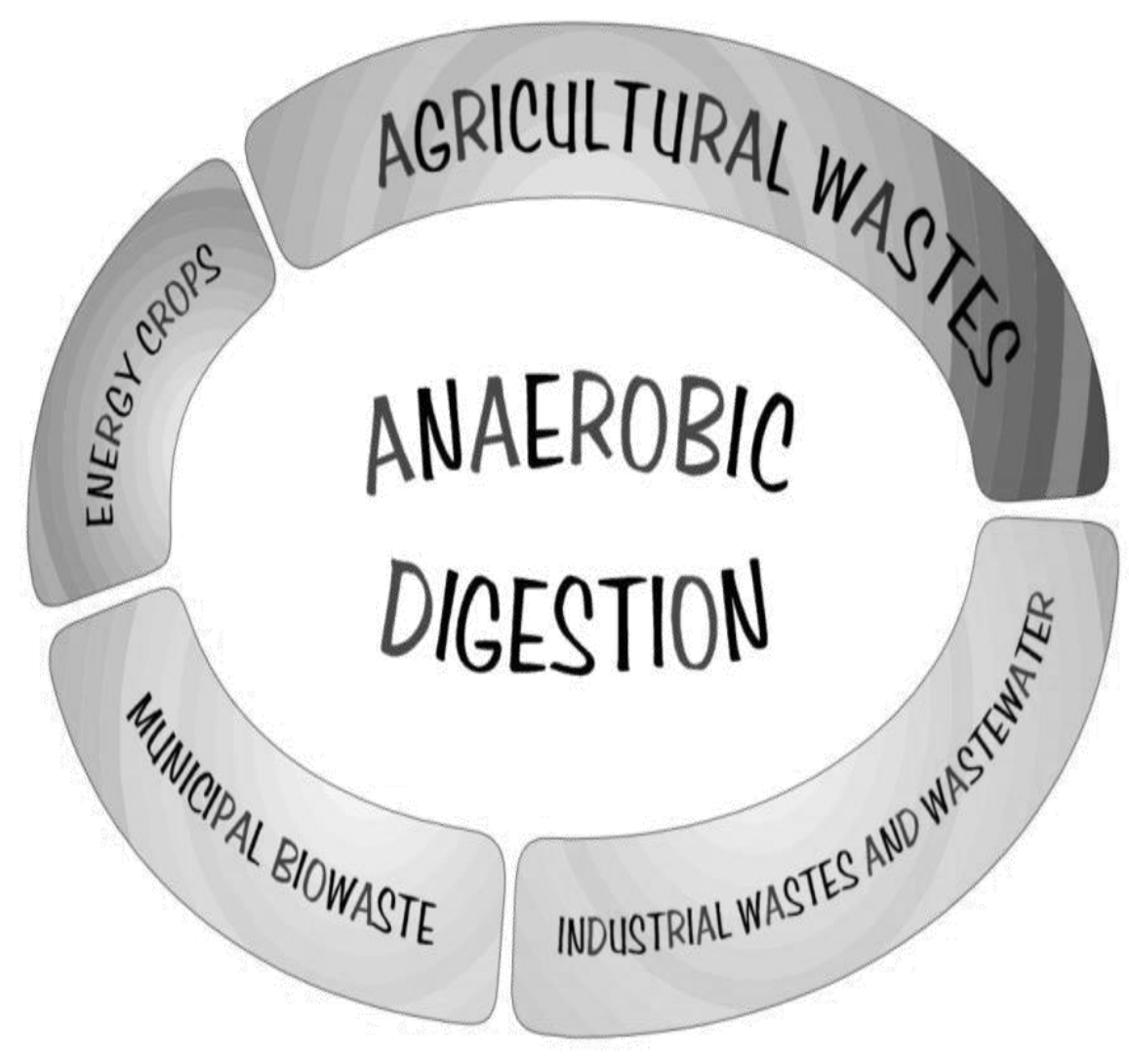

Figure 3: Several feedstocks for treatment source (Steffen \& Szolar, 1998) 


\section{General Process Description}

The anaerobic digestion process is used in the treatment of domestic and industrial wastewater. In the process, both solid waste, as well as liquid organic waste, can be anaerobically treated. The aim of this process is not only to produce the methane but also reduce the volume of solid waste. The organic waste that feeds the anaerobic process is composed of carbon, nitrogen, and oxygen. Microorganism uses those organics as a substrate for growth and accommodates with water to form carbon dioxide and methane (Jarvie, 2017). The actual breakdown of organics to its end product methane is not performed by a single process but occurs in different steps which were already described above.

The process of the $A D$ is divided into four stages:

I. Pre-treatment

II. Digestion

III. Gas upgrading \&

IV. Digestate treatment

The pre-treatment depends upon the type of feedstock like manures are mixed whereas MSW is separated and sorted. In the second stage, different kind of digester depending on the solid content, the digester can be dry or wet with different temperature and mixing devices. The temperature plays a crucial role here as the efficiency of the digester depends on the temperature. In the third stage, the impurities present can damage boilers and engine, so the gas was upgraded. For the upgradation, hydrogen sulphide and water vapours are removed from the boilers. The figure 4 below shows the process of digestion when two different types of waste are mixed in digestion plant (Monnet, 2003). 


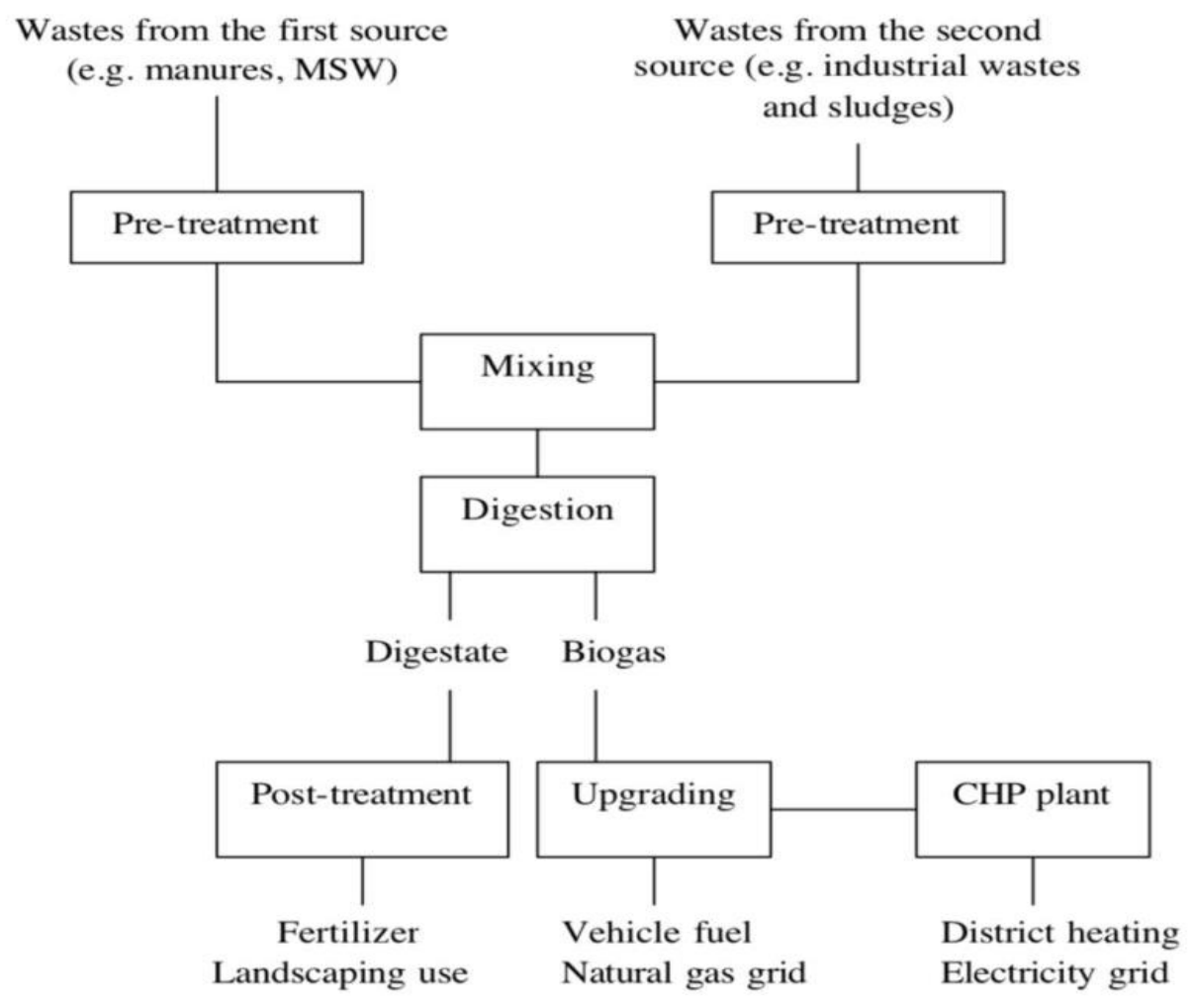

Figure 4: General process for anaerobic digestion plan Source (Monnet, 2003)

\section{Environmental Factors \& Operational Parameters Influencing AD}

Anaerobic digestion performance can be affected by serval factors such as loading, temperature and mixing. More details on the known factors are listed below.

\subsection{Total Solid Content}

There are different ranges of solid content: low solid contains $10 \% \mathrm{TS}$, medium solid range from $15-20 \%$ TS and high solid from $22-40 \%$ TS. With the increase in the total solid content, the volume of the digester decreases (Jing, 2014). 


\subsection{Organic Loading Rate}

Organic loading rate $(O L R)$ is a measure of biological conversion capacity of the $A D$ system. Feeding the system above its sustainable OLR results in low biogas yield due to the build-up of inhibiting substances such as fatty acids in the digester slurry. Under such circumstances, the feeding rate of the system must be reduced. OLR is a particularly important control parameter in continuous systems. Many plants have reported system failure due to overloading. It is linked with retention time for any particular feedstock and anaerobic reactor volume (Verma, 2002).

\subsection{Temperature}

Temperature is one of the most important parameters in anaerobic digestion. It determines the rate at which process works for hydrolysis and Methanogenesis (Nayono, 2010). The $A D$ can occur in two stages of temperature 1) mesophilic $\left(25-45^{\circ} \mathrm{C}\right)$ and 2$)$ thermophilic $\left(45-65^{\circ} \mathrm{C}\right)(\mathrm{CHEN}$, july 2010). Most of the full-scale $A D$ are operated at mesophilic temperature due to several advantages like high organic removal rate, a high degree of degradation, and solid stabilization. Microbial communities involved in the digestion are sensitive to low temperature so thermophilic digesters are more efficient in terms of retention time, loading rate and gas production but they need higher heat input which makes the process more complicated than mesophilic digestion (Verma, 2002).

\section{4 power of Hydrogen $(\mathrm{pH})$}

$\mathrm{pH}$ is a significant factor in keeping functional anaerobic digestion. The acid concentration in the aqueous system is expressed by $\mathrm{pH}$ value that means the concentration of hydrogen ions. Under neutral conditions, the solution has a value of $\mathrm{pH} 7$. While the acid solution has a $\mathrm{pH}$ value less than 7 whereas alkaline solution has been at a higher value of $\mathrm{pH}$ 7. In case of an $\mathrm{AD}$, the process requires two different $\mathrm{pH}$ values for acidification process and Methanogenesis process. Acetogenesis can lead to accumulation of acids which will drop the $\mathrm{pH}$ during fermentation. To maintain the stability of the operation, 
bicarbonate and carbonate are added as alkalinity buffer to neutralize volatile fatty acids and carbon dioxide (CHEN, July 2010).

As the digestion reaches the Methanogenesis stage, the $\mathrm{pH}$ value can reach above 8 as an increase in the concentration of ammonia. Once methane production is stabilized, the $\mathrm{pH}$ level remains between 7.2- 8.2 (Verma, 2002).

\subsection{Hydraulic Retention Time}

Hydraulic retention time (HRT) is the average time that sludge resides in the digester. If $\mathrm{HRT}$ is shorter, the system will fail due to the washout of slowest growing microorganisms that are necessary for the anaerobic process. HRT of solid waste typically varies from 355 days depending on the type of waste, temperature, and configuration of digesters. HRT for dry anaerobic digestion lies between 14-30 days whereas for wet anaerobic digestion it can be as low as 3 days (Nayono, 2010).

\subsection{Solid Retention Time}

In the studies, it was found that volatile fatty acids yields increased with a solid retention time (Zhang, Li, Jia, Dai, \& Zhao, Sept 2015). The retention is the time taken by organic matter to complete the degradation process. The optimum value for the SRT will be a function of waste composition, operating temperature and various another process. The SRT is very important to design parameter for carbon conversion as it has to be in the reactor for the optimum time to perform metabolism and produce methane. (Manser, January 2015).

\subsection{Mixing}

Reactor mixing is a compelling operational parameter for anaerobic digesters. Three types of mixing used in anaerobic digestion system are continuous, intermittent and minimal. Regarding the mixing types, there are conflicts between the result for each type (Manser, January 2015). So far, continuous mixing improved production of methane as compared to another mixing. To eliminate the energy demand for mixing additional research can be carried out for better knowledge and understanding. 


\subsection{Other Parameters}

Chemical additives can enhance the VFA production during anaerobic digestion. Additives like sodium dodecyl benzene sulfonate (SDBS) and $\beta$-cyclodextrin can change the surface properties and improve the dissolubility of excess sludge. Increase in VFA production will lead to decrease in methane production. It was also noted that VFA production increased significantly regardless of any mesophilic or thermophilic temperature conditions. These additives are costly, but there might be some cheap and environmentally friendly additives which can help to improve the VFA production during anaerobic digestion of excess sludge (Khan, 2016).

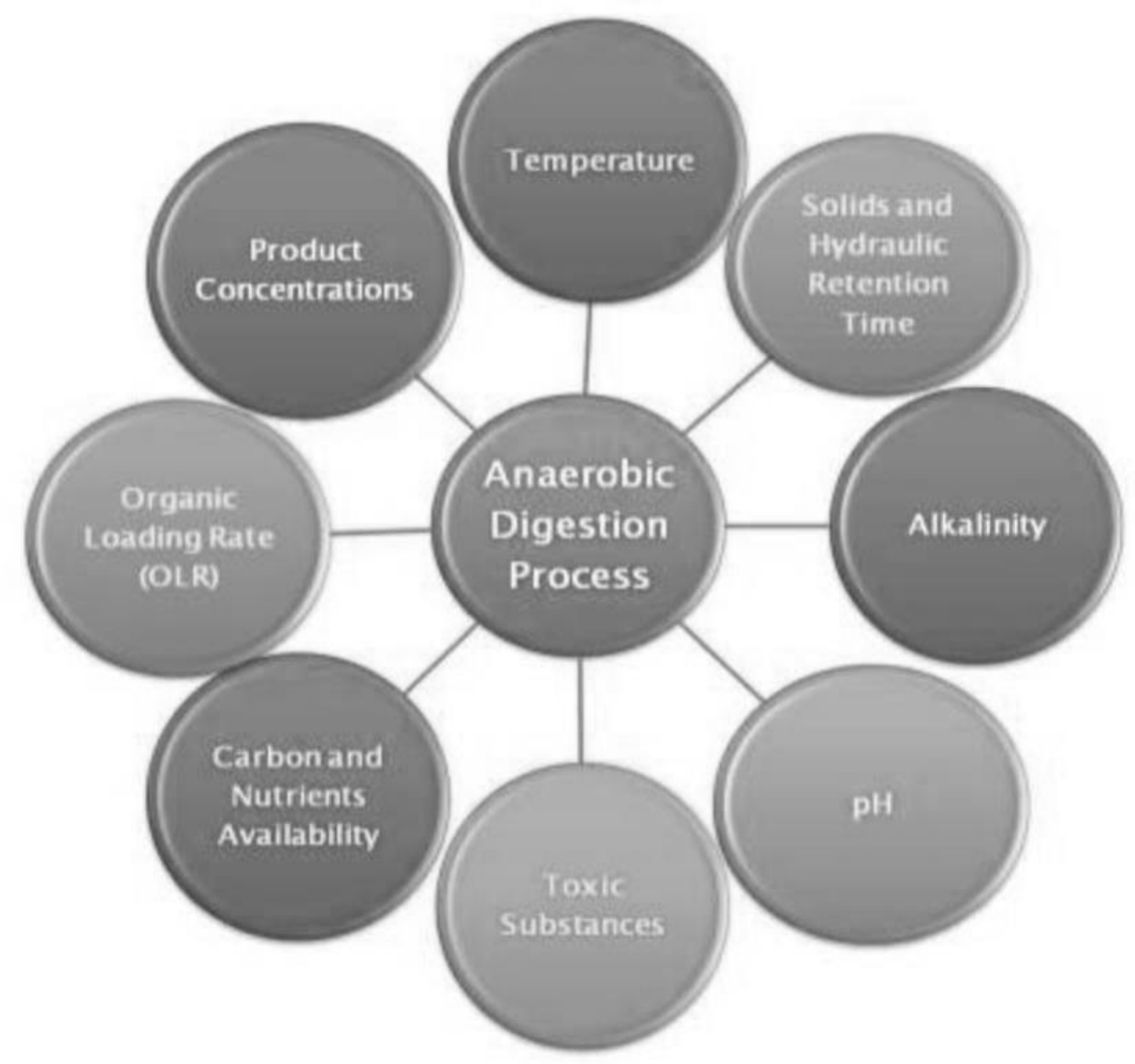

Figure 5 : Operational parameters for anaerobic digestion Source (Yang, 15 December 2015) 


\section{Literature Review for Volatile Fatty Acid Models}

\subsection{Introduction}

Volatile fatty acids (VFA) are the intermediate product formed in acidification of $A D$ process in which most ordinary are short-chain fatty acids with two to six carbons like acetic, butyric, and propionic acid. These intermediate products in the AD process may be biologically produced from organic waste such as carbon sources, such as waste activated sludge, food waste, paper mill effluent and soft drink wastewater.

Fermentation of organic waste to produce VFA help in reduction of carbon footprint and waste disposal. For VFA production, the process occurs in two steps first hydrolysis of organic matter to soluble compounds and second step acidification of the soluble compounds from hydrolysis to products such as VFA, lactate, and ethanol. The hydrolysis and acidification are a function of various operational parameters which are already discussed in section 3.1. Appels et al., 2008 tated that mainly acetic and butyric acids are produced at low $\mathrm{pH}$ using wasted activated sludge whereas $\mathrm{pH}$ near 8 mainly produced propionic acid. Lee at el., in his report also stated, higher propionic acid was produced at pH 4 from dairy wastewater (Lee, 2014). Regarding VFA production, total solids (TS) content inside the reactor also depends on the efficiency of the process taking place. It is reported that high content of TS leads to a decrease in the formation of methane due to mass transfer limitations.

The production of VFA from the organic waste has an extensive range of applications which include bioenergy production such as electricity, biohydrogen, and lipids for biodiesel (Lee, 2014). The higher content in acetic or butyric acids in acidification phase is appropriate for methane formation. 


\section{Models for VFA Production}

For the VFA production, the mathematical modeling was used as a method of analysis for degradation kinetics. Various models have been attempted, the development of simulation model involves numerous simplifications concenring the processes that take place in the system. The model includes selected set of variables, defined equations of substrate, and model coefficients. Some of the developed models are described briefly and characterize the operational factors which affected the process (Lokshina, 1996).

\subsection{First Order Model}

In order to describe the dark fermentation process of primary sludge using the first order reaction is the most common method concerning the initial concentration of potential VFA. In the batch reactor experiment, it has been observed that VFA production start immediately and increases until its maximum concentration achieved which is usually after 8 days. Also, in the hydrolysis process, where lipids and carbohydrates of organics degrade at a faster rate, but protein is the rate-limiting step in the $A D$ which also account for the extensive rate constant of hydrolysis.

\subsection{Steady State Acid Fermentation Model}

Fermentation of primary sludge from a treatment plant in cape town, South Africa was experimented in a batch reactor to study the effects of solid concentration. The experiment was performed across a range of influent VSS from $11 \mathrm{~g} \mathrm{VSS/L} \mathrm{to} 42 \mathrm{~g} \mathrm{VSS/L}$. It were noted that fermentation kinetics per unit VSS is independent of VSS concentration with no concentration effect could be detected. The equation 1 below express the VFAs formation is a first order reaction with potential VFAs remaining per initial VSS.

$$
\frac{\mathrm{d}\left(\mathrm{VFA}_{\mathrm{tvo}}^{\prime}\right)}{\mathrm{dt}}=-\mathrm{k} * \mathrm{VFA}_{\mathrm{pvo}}^{\prime}
$$

whereas, VFA'tvo $=$ concentration in mg of VFA as per COD per mg of initial VSS at any time t. 


$$
\begin{aligned}
& \mathrm{K}=\text { first order reaction consntant. } \\
& V F A^{\prime} \text { pvo = potential } \mathrm{mg} \text { of VFA as COD per mg of initial VSS }
\end{aligned}
$$

In order to solve the above expression, VFA'pvo and k should be determined from the experimental result. All the value of VFA'tvo is calculated and plotted against time in the graph. The straight line in the graph yield the best value for VFA'pvo and the $k$ is determined from equation 2 and the slope $(\mathrm{m})$ of the straight line.

$$
m=-k * \log _{10} e
$$

Eq 2

In the reported value, the maximum potential conversion of influent COD to VFA at $20^{\circ} \mathrm{C}$ for primary sludge at retention time less than 10 days was 17\% (Lilley, 1990). Later, it was recommended that the fermentation system should not exceed 6 days retention time as there may be a methanogenic activity which will reduce the yield of VFA production.

\subsection{Anaerobic Digestion Model No 1}

The Anaerobic Digestion Model No 1 build based on the Activated Sludge Model. ADM No 1 model uses first order kinetics for the hydrolysis stage and, for a most fundamental approach that can take the range of disintegration processes. Primary sludge and waste activated sludge is assumed to first disintegrate into carbohydrate, protein, and lipid particulate substrate and then undergoes hydrolysis (Albornoz, 2017). The first order disintegration step with respect to the composite waste material is expressed in

$$
r_{\text {dis }}=k_{\text {dis }} * X_{\text {composite }}
$$

where, rdis $=$ rate of disintegration

$$
\begin{aligned}
& \mathrm{K}_{\mathrm{dis}}=\text { first-order disintegration constant } \\
& \mathrm{X}_{\text {composite }}=\text { composite waste material }
\end{aligned}
$$

After the disintegration of the composite material into carbohydrates, lipids, and proteins three parallel conduits happens to each component. This separation is very important as it will yield the three different products through the hydrolysis of three different conduits. 
First order rate of carbohydrate with respect to particulate carbohydrate concentration was expressed in equation 4

$$
r_{h y d, c h}=k_{h y d, c h} * X_{c h}
$$

where, $\mathrm{r}_{\text {hyd, }}$, $=$ rate of carbohydrate hydrolysis

$$
\begin{aligned}
& \mathrm{K}_{\mathrm{hyd}, \mathrm{ch}}=\text { first-order carbohydrate hydrolysis constant } \\
& \mathrm{X}_{\mathrm{ch}}=\text { carbohydrate concentration }
\end{aligned}
$$

The product of equation 4 produces monosaccharides which are uptake by the sugar to produce VFA as described in equation 5.

$$
r_{s u}=k_{m, s u} \frac{s_{s u}}{k_{s}+s_{s u}} X_{s u} * I_{1}
$$

Where $r_{s u}=$ rate of sugars uptake

$$
\begin{aligned}
& \mathrm{K}_{\mathrm{m}, \mathrm{su}}=\text { specific Monod maximum uptake rate constant for sugars } \\
& \mathrm{K}_{\mathrm{s}}=\text { Monod half-saturation constant } \\
& \mathrm{S}_{\mathrm{su}}=\text { Sugar concentration } \\
& \mathrm{X}_{\mathrm{su}}=\text { sugar degraders } \\
& \mathrm{I}_{1}=\text { Inhibition function }
\end{aligned}
$$

Similarly, first order reaction rate of hydrolysis of proteins and lipids with respect to particulate protein concentration and lipid concentration respectively produce the VFA production when the product of the reaction in equation 6 , i.e. amino acids, whose uptake produce VFA from proteins expressed in equation 7

$$
r_{h y d, p r}=k_{h y d, p r} * X_{p r}
$$

where, rhyd,pr = rate of protein hydrolysis 
khyd,pr = first-order protein hydrolysis constant

$$
\mathrm{X}_{\mathrm{pr}}=\text { protein concentration }
$$

$$
r_{a a}=k_{m, a a} \frac{s_{a a}}{k_{s}+s_{a a}} X_{a a} * I_{1}
$$

Where, raa $=$ rate of amino acids uptake

$$
\begin{aligned}
& \mathrm{k}_{\mathrm{m}, \mathrm{aa}}=\text { specific Monod maximum uptake rate constant for amino acids } \\
& \mathrm{K}_{\mathrm{s}}=\text { Monod half-saturation constant } \\
& \mathrm{S}_{\mathrm{aa}}=\text { amino acids concentration } \\
& \mathrm{X}_{\mathrm{aa}}=\text { amino acids degraders }
\end{aligned}
$$

In case of lipids, the product of the reaction produces long chain fatty acids as described in equation 8 whose uptake will produce hydrogen gas and acetate according to the rate as expressed in equation 9.

$$
r_{h y d, l i}=k_{h y d, l i} * X_{l i}
$$

Eq 8

where, rhyd,i $=$ rate of lipids hydrolysis

$\mathrm{k}_{\text {hyd,ii }}=$ first-order lipids hydrolysis constant

$\mathrm{X}_{\mathrm{i}}=$ lipids concentration

$$
r_{f a}=k_{m, f a} \frac{s_{f a}}{k_{s}+s_{f a}} X_{f a} * I_{1}
$$

where $\mathrm{rta}_{\mathrm{fa}}$ rate of fatty acids uptake

$$
\begin{aligned}
& \mathrm{k}_{\mathrm{m}, \mathrm{fa}_{\mathrm{a}}}=\text { specific Monod maximum uptake rate constant for fatty acids } \\
& \mathrm{K}_{\mathrm{s}}=\text { Monod half-saturation constant } \\
& \mathrm{S}_{\mathrm{fa}}=\text { fatty acids concentration } \\
& \mathrm{X}_{\mathrm{fa}}=\text { Long-chain fatty acid degraders }
\end{aligned}
$$


The main disadvantage of this method is that the substrate fraction of carbohydrate, protein and lipid content must be characterized which is very difficult in routine practice. Another drawback for the first-order model is that there is no limit for maximum rate whereas, the equation suggests an increase in component would increase the rate infinitely (Albornoz, 2017).

\subsection{Surface Limiting Model}

Surface limiting model is an alternate model to measure the rate of hydrolysis as a function of the biodegradable particulate substrate for surface limiting model. This observation was regarded as surface limiting model, causing mass transfer limitations. The aim of this model was to actually reduce the number of variables while still producing VFA. In this model, instead of distinguishing individual VFA, the sum of VFA was considered. The equation 10 below shows that mass balance equation for VFAs in the model

$$
\frac{d C_{V F A}}{d t}=\frac{1}{H R T}\left(C_{V F A}^{i n}-C_{V F A}\right)+\left(1-Y_{a}\right) * r_{x, a}-r_{x, m}
$$

where $\mathrm{C}_{\mathrm{VFA}}=$ concentration of VFA

$Y_{a}=$ acidogenic biomass yield

$r_{x, a}=$ reaction rate for acidogenic biomass growth

$$
r x, a=U m a x, a \frac{C m o \quad C N H 4-N}{(K a+C m a)(K n+C N H 4-N)} C x, a
$$

$$
r_{x, m}=\text { reaction rate for methanogenic biomass growth }
$$

$$
r x, m=U m a x, m \frac{C m o \quad C N H 4-N}{(K a+C m o)(K n+C N H 4-N)} C x, m
$$

It was found that surface limiting model was able to explain and describe the steady state result with respect to the effect of retention time over 3.5 days on effluent VFA (Albornoz, 2017) but model did not consider the effects of mixing intensity, temperature and chemical inhibitors on the rate of VFA production (Münch, 1999) 


\section{Material and Methods}

This section describes the apparatus and methods that were employed to analyze the semi-continuous fermentation process using source separated organics as substrate. This experiment was performed for the production of volatile fatty acids for raw and pretreated source separated organics. The pre-treated SSO sample was hydro-thermalized at $170{ }^{\circ} \mathrm{C}$ as described in section 9.3. (Lokshina, 1996)

Table 1: Average properties of feed source separated organics

\begin{tabular}{|c|c|c|}
\hline \multicolumn{2}{|c|}{ Average properties of feed source separated organic } \\
\hline Parameters & Raw SSO & Pre-treated SSO \\
\hline pH & 5.55 & 5.45 \\
\hline TSS (mg/L) & 62242 & 42904 \\
\hline VSS (mg/L) & 45383 & 30967 \\
\hline SCOD (mg/L) & 32498 & 47950 \\
\hline TCOD (mg/L) & 99183 & 98617 \\
\hline Ammonia (mg/L NH 3 -N) & 867 & 927 \\
\hline
\end{tabular}




\subsection{Substrate}

In this experiment, Source Separated Organic (SSO) was used as the feedstock for the fermentation process. Source Separated Organics was obtained from Disco Road facility and stored separately in a refrigerator that keeps the samples at $4^{\circ} \mathrm{C}$. Disco road facility rolled out in 2002 and Source Separated Organic mostly consists of food waste, pet waste, wet paper, sanitary products and household plants, etc.

\subsection{Experimental set-up and procedures}

The experimental work was initiated by feeding the digesters with SSO (raw and pretreated) to study the fermentation process under anaerobic condition. Figure 6 displays the experimental set-up of SSO raw and SSO pre-treated reactor with a working volume of 1.5 litres each. The temperature was maintained at $38^{\circ} \mathrm{C}$ (mesophilic) using a water bath tub. The reactors were equipped with stir to maintain homogeneity at $150 \mathrm{rpm}$. Also, the tedler gas bag was connected to the reactor to check for methane production.

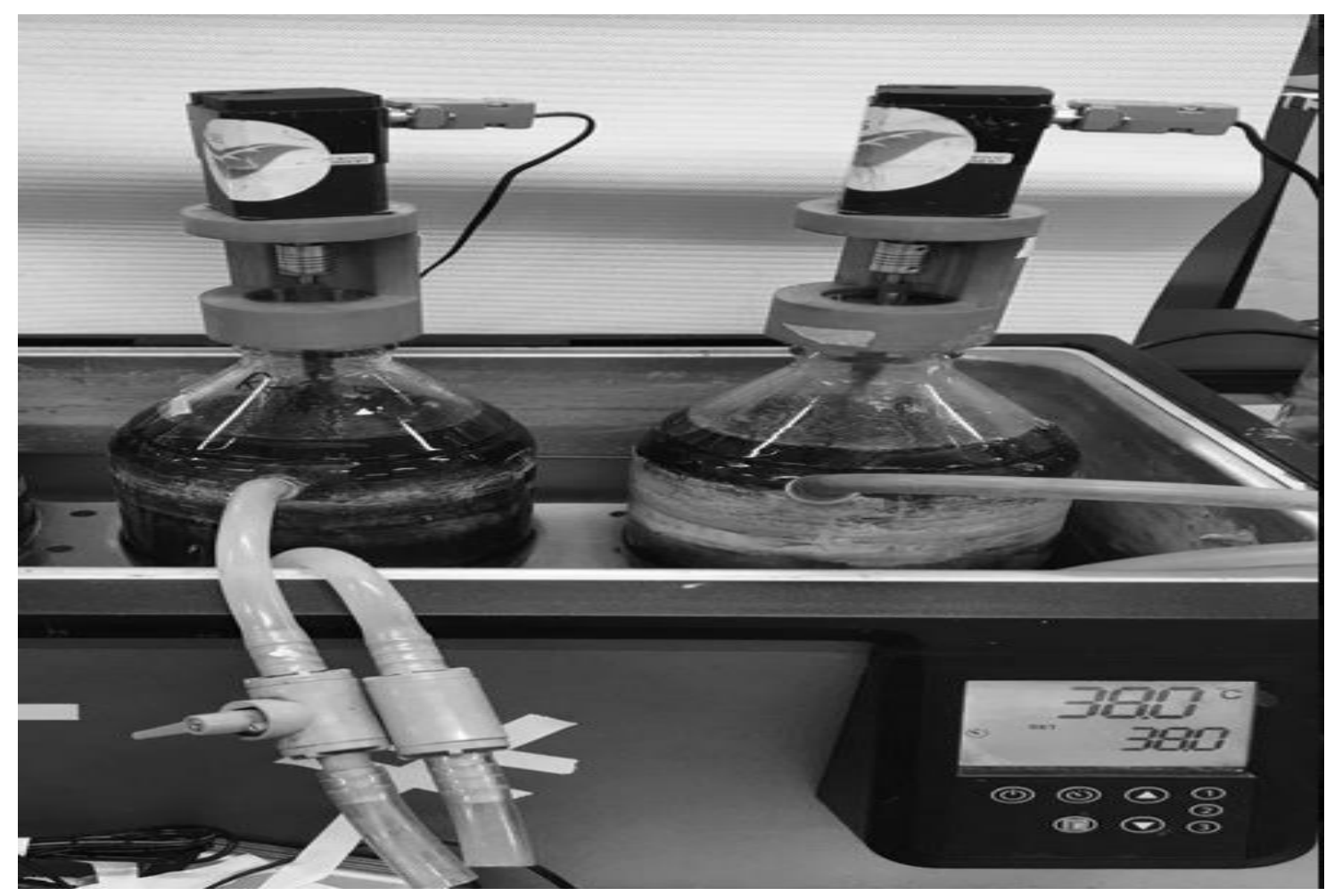

Figure 6: Experimental anaerobic digester setup. Raw (left) \& pretreated (right) SSO. 
During feeding, the reactors headspace was purged with nitrogen gas in order to maintain anaerobic condition and to prevent vacuum formation in the digester. Each digester had two valves, lower one for sampling and upper one for feeding. Sampling and feeding were performed using the syringe pump. Every day $500 \mathrm{ml}$ out of $1500 \mathrm{ml}$ substrate was taken out, and a new $500 \mathrm{ml}$ substrate was fed into the digester in order to maintain retention time for 3 days and, the experiment was run for 6 weeks.

Table 2: Frequency of sample analysis

The frequency of sample Analysis

\begin{tabular}{|c|c|c|}
\hline Activities & Influent & Effluent \\
\hline Feeding & Everyday & Everyday \\
\hline $\begin{array}{c}\text { Chemical Oxygen } \\
\text { Demand }\end{array}$ & Once a week & Twice a week \\
\hline VFA & Once a week & Twice a week \\
\hline Ammonia & Once a week & Twice a week \\
\hline Alkalinity & Once a week & Twice a week \\
\hline Carbohydrates & Once a week & Twice a week \\
\hline
\end{tabular}




\subsection{Hydro-thermal procedure}

Hydrothermal pre-treatment was done by Parr 4848 Hydrothermal Reactor with a capacity of $2 \mathrm{~L}$ at one time of operation. However, the volume of each pre-treatment in this study was 1.5 liter. The heating rate of materials initially were $2{ }^{\circ} \mathrm{C}$ per minute and then was reduced to $1{ }^{\circ} \mathrm{C}$ per minute. During the pre-treatment, the SSO was constantly mixed and operated by specView Parr 4848 controller and hydrothermal pre-treatment rate was recorded accordingly.

In the hydro-thermal process, the raw sludge was treated at $170^{\circ} \mathrm{C}$. Figure 7 Shows the hydro-thermal set-up. It was run on ramp/soak pattern. The pattern consisted of 4 steps raising the temperature from $20^{\circ} \mathrm{C}$ to $170^{\circ} \mathrm{C}$ in certain time periods as shown in figure 8. To bring the substrate to room temperature, another setup for cooling the system was attached to the hydro-thermal and, also can be seen in figure 9 that after reaching $170^{\circ}$ C temperature graph significantly fall to room temperature.

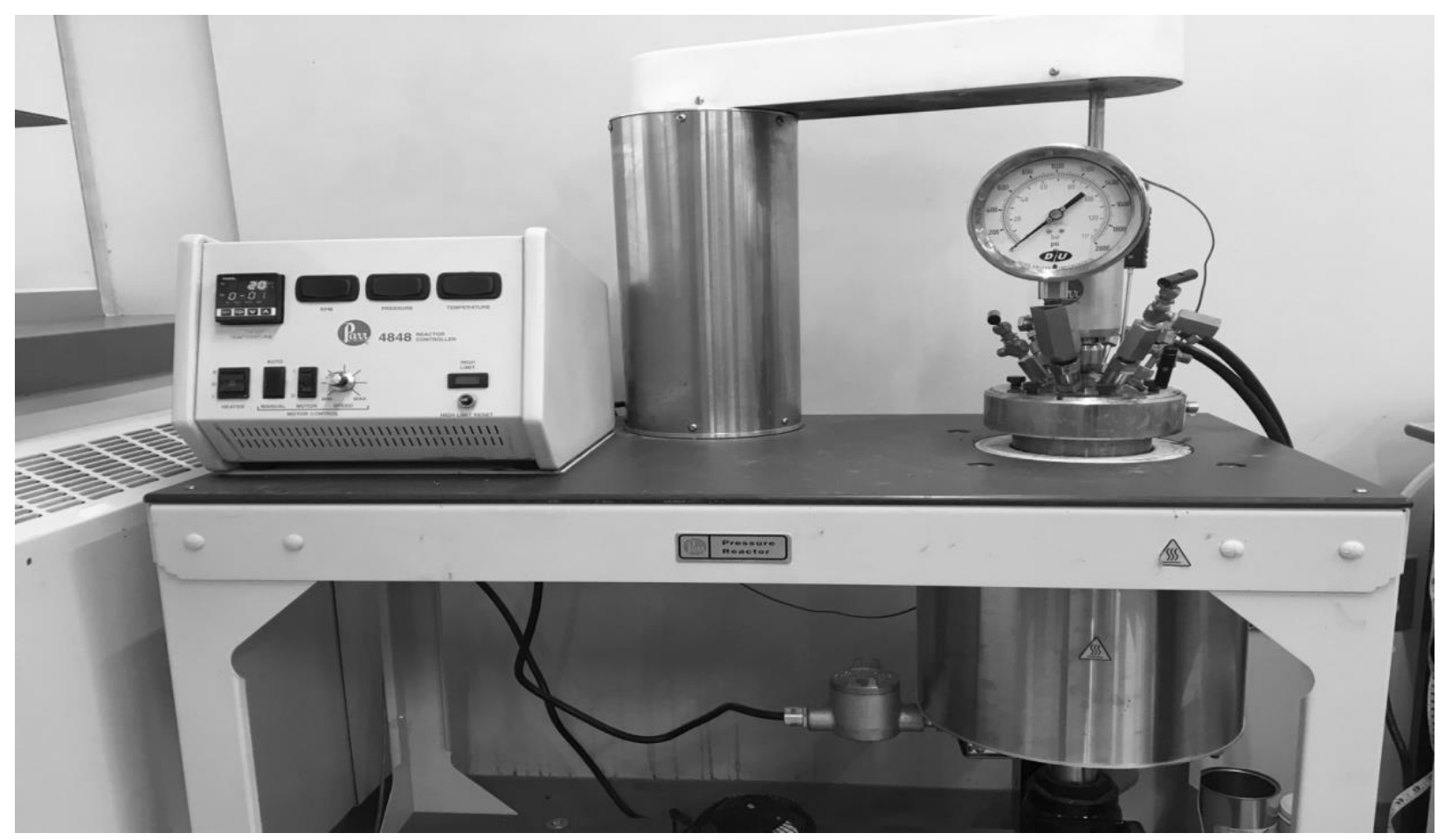

Figure 7 : Parr 4848 pressure reactor 


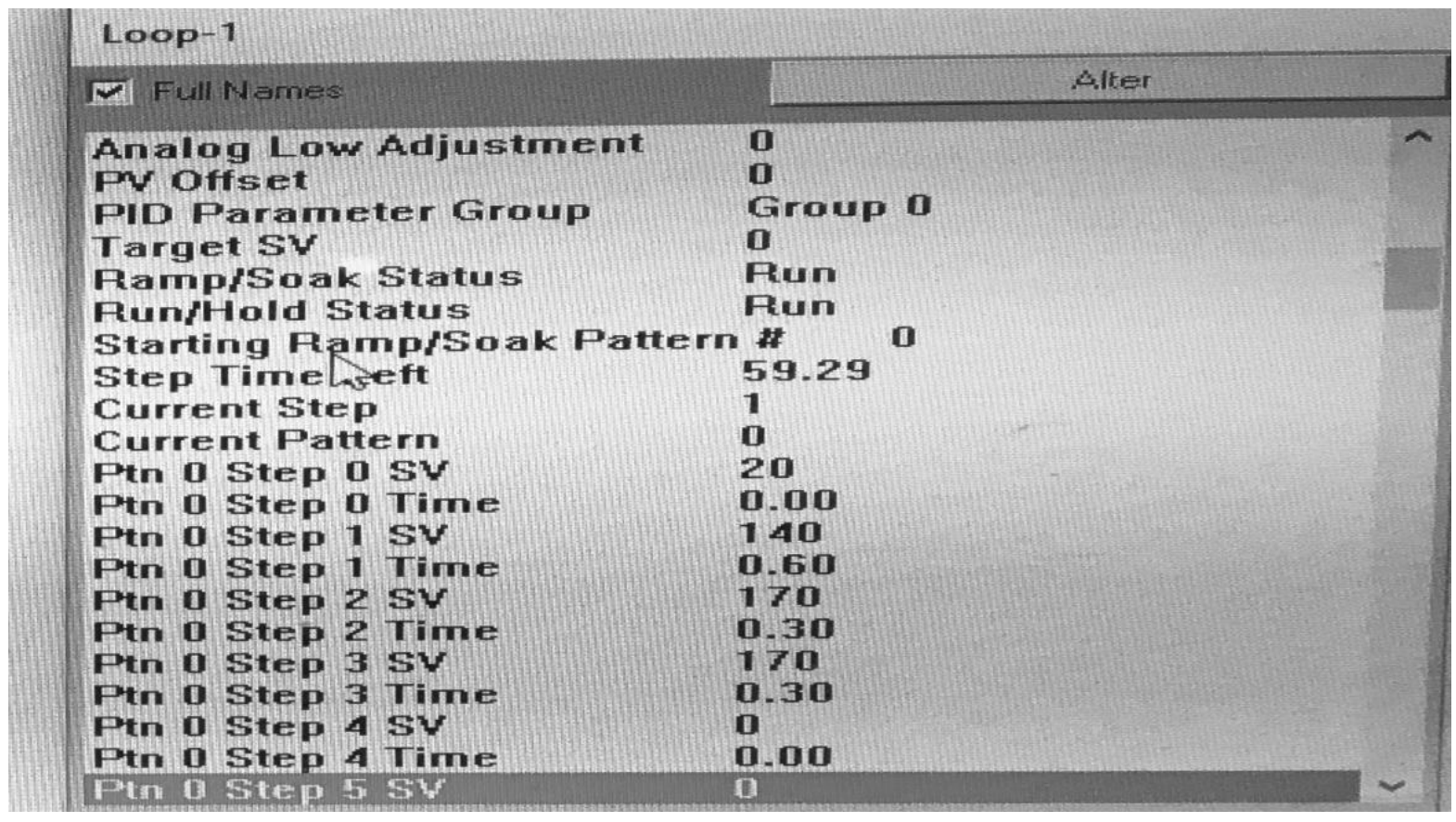

Figure 8: Temperature pattern for hydro-thermal

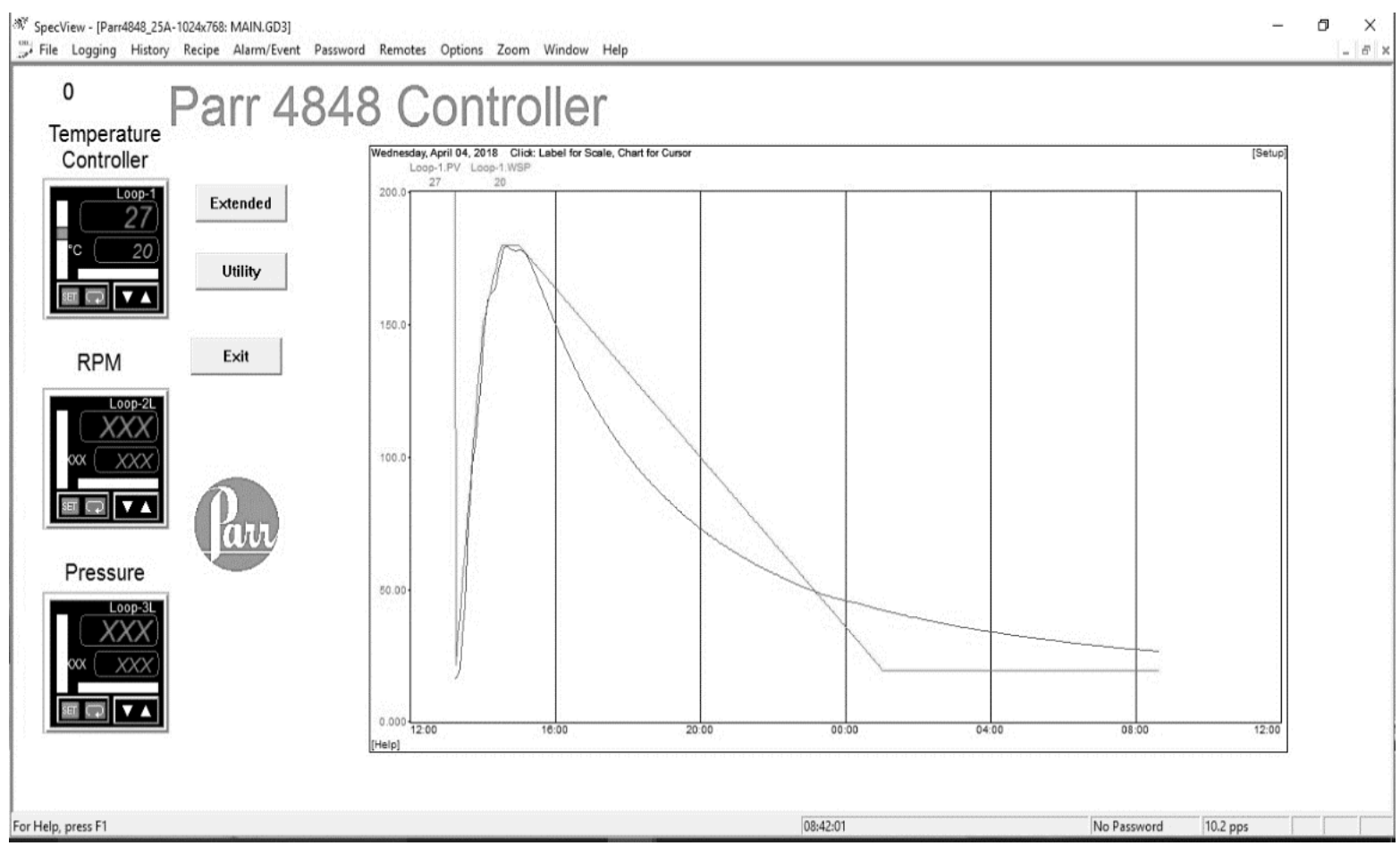

Figure 9: Parr 4848 controller showing temperature graph 


\section{Sample Analyses}

All the analyses that were completed and carried out in triplicates, the complete procedure for each test are listed below.

\section{$10.1 \mathrm{pH}$}

The $\mathrm{pH}$ of each sample was measured immediately; it was collected using VWR Benchtop $\mathrm{pH}$ Meter and refillable glass probe, model $\mathrm{AB} 15$ as shown in figure 10 was employed to measure $\mathrm{pH}$ for all the samples. This meter was calibrated twice a week with $\mathrm{pH}$ reference standards.

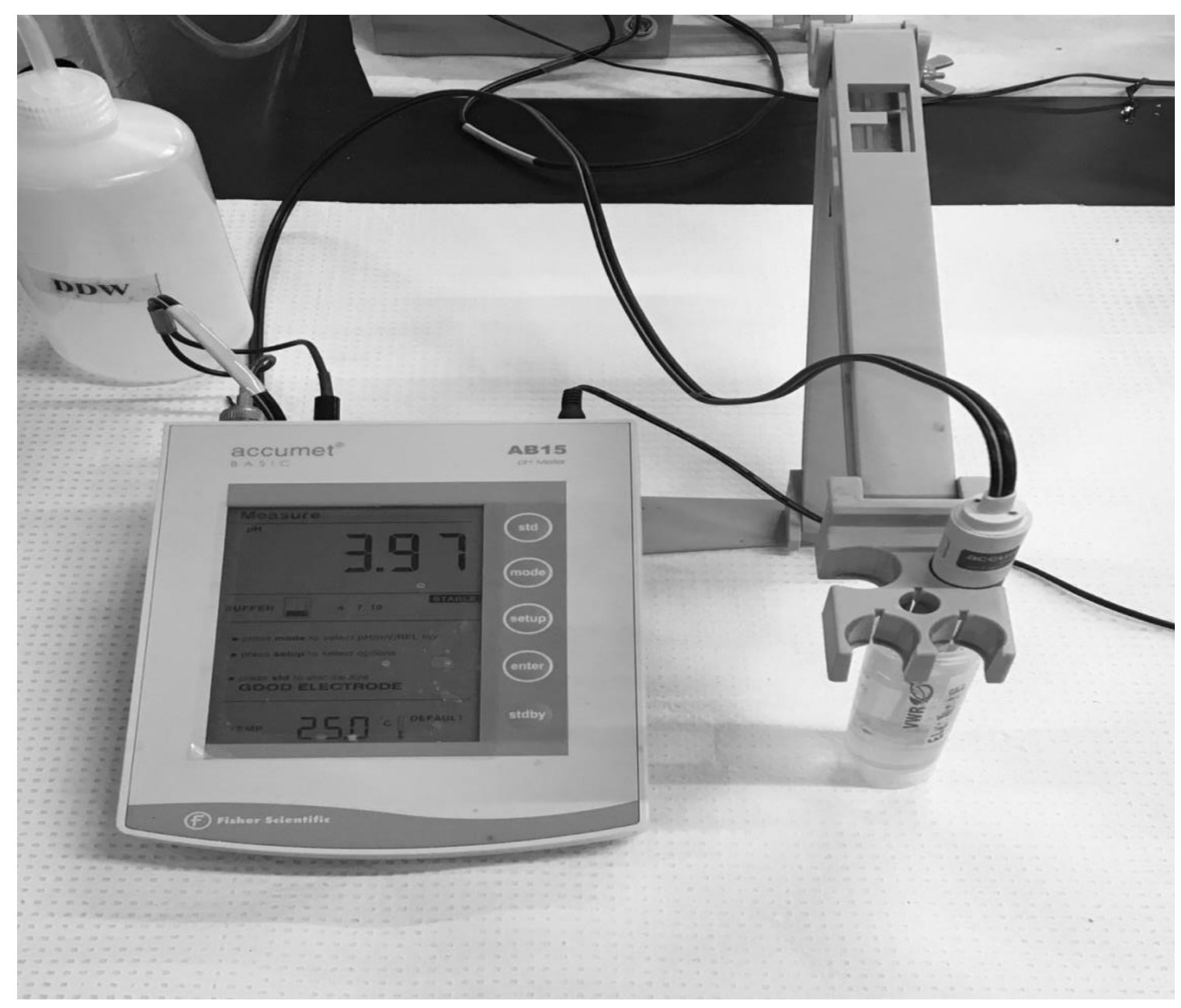

Figure 10: $\mathrm{pH}$ meter fisher scientific model $A B 15$ 


\subsection{TS/VS}

The standard guidelines were followed provided in 2540B and 2540E for TS and VS respectively.

\subsection{TSS/VSS}

Standard methods 2540D and 2540E was employed to measure TSS and VSS respectively. $2 \mathrm{ml}$ of each sample using $1.5 \mu \mathrm{m}$ glass microfiber filter paper for filtration and then drying in the oven at $105^{\circ} \mathrm{C}$ for 1 hour for TSS. The mass of the samples was measured and was placed in a furnace for 20 minutes at $550^{\circ} \mathrm{C}$. After combustion, plates were measured, and the weight loss represented as VSS.

\subsection{Chemical Oxygen Demand (Total / Soluble)}

High range (20-1500mg/L) COD reagent vials from HACH were used to follow method 8000. For sample analysis, the tests were conducted in triplicates. For soluble COD, the sample was centrifuged at $9800 \mathrm{rpm}$ for 30 minutes as shown in figure 11. After centrifuged, the sample was filtered with $0.45 \mu \mathrm{m}$ and diluted with an appropriate dilution factor. $2 \mathrm{ml}$ of diluted sample was added to the vial and blank was also prepared for $2 \mathrm{ml}$ of DDW. The vials were inverted 10 times before digestion in the COD reactor for 2 hours at $150^{\circ} \mathrm{C}$. The samples were measured using $\mathrm{HACH}$ DR 3900 spectrophotometer.

\subsection{Ammonia}

High range (0.4 - $50 \mathrm{mg} / \mathrm{L})$ Amver Ammonia reagent set were used as per Method 10031, the Salicylate method. Concentrations of ammonia were determined using the HACH DR3900 spectrophotometer.

\subsection{VFA}

Esterification method TNT 872 reagent set (range 50 to $2500 \mathrm{mg} / \mathrm{L}$ ) were used as per standard method 10240. Concentrations of volatile acids were determined using the HACH DR3900 spectrophotometer. 


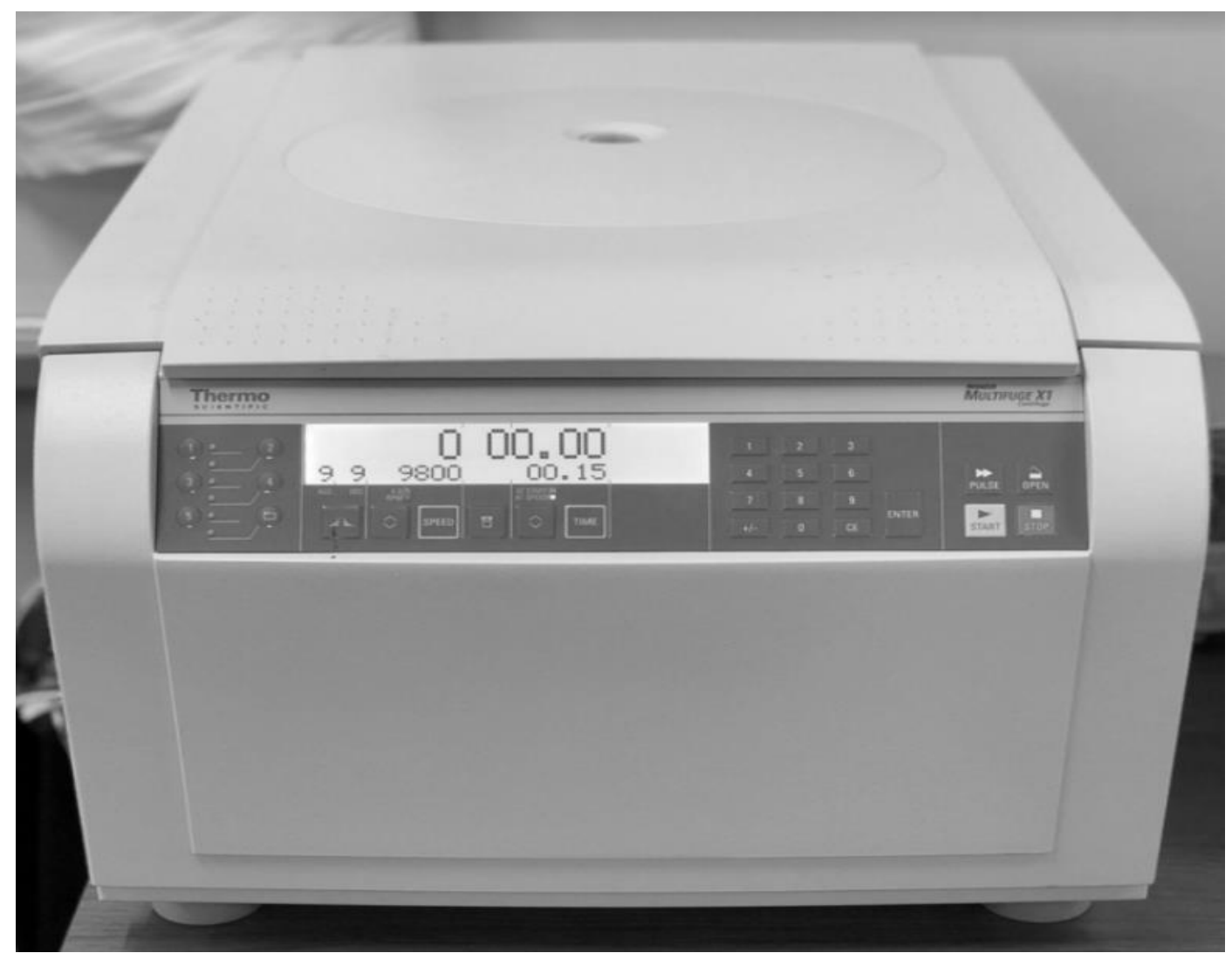

Figure 11: Thermo fisher scientific centrifuge machine

\subsection{Carbohydrates (Total / Soluble)}

The carbohydrates concentration is measured calorimetrically as glucose because SSO mainly constitute of food waste, using the phenol-sulfuric method. A standard calibration curve with glucose at concentrations of $5-1000 \mathrm{mg} / \mathrm{L}$ must be prepared. Deionized water is used as blanked. The reagent used was standard glucose, concentrated sulfuric acid, phenol $5 \% \mathrm{w} / \mathrm{v}$ (weight/volume).

\subsection{Alkalinity}

High range (25 - $400 \mathrm{mg} / \mathrm{L} \mathrm{CaCO}_{3}$ ) total Alkalinity TNT 870 reagent set were used as per method 10239. Moreover, the concentration of Alkalinity was determined using Hach DR3900 spectrophotometer. 


\section{Results and discussion}

Figure 12 shows the average result of TS and VS which was done in triplicate for the raw and pre-treated samples.

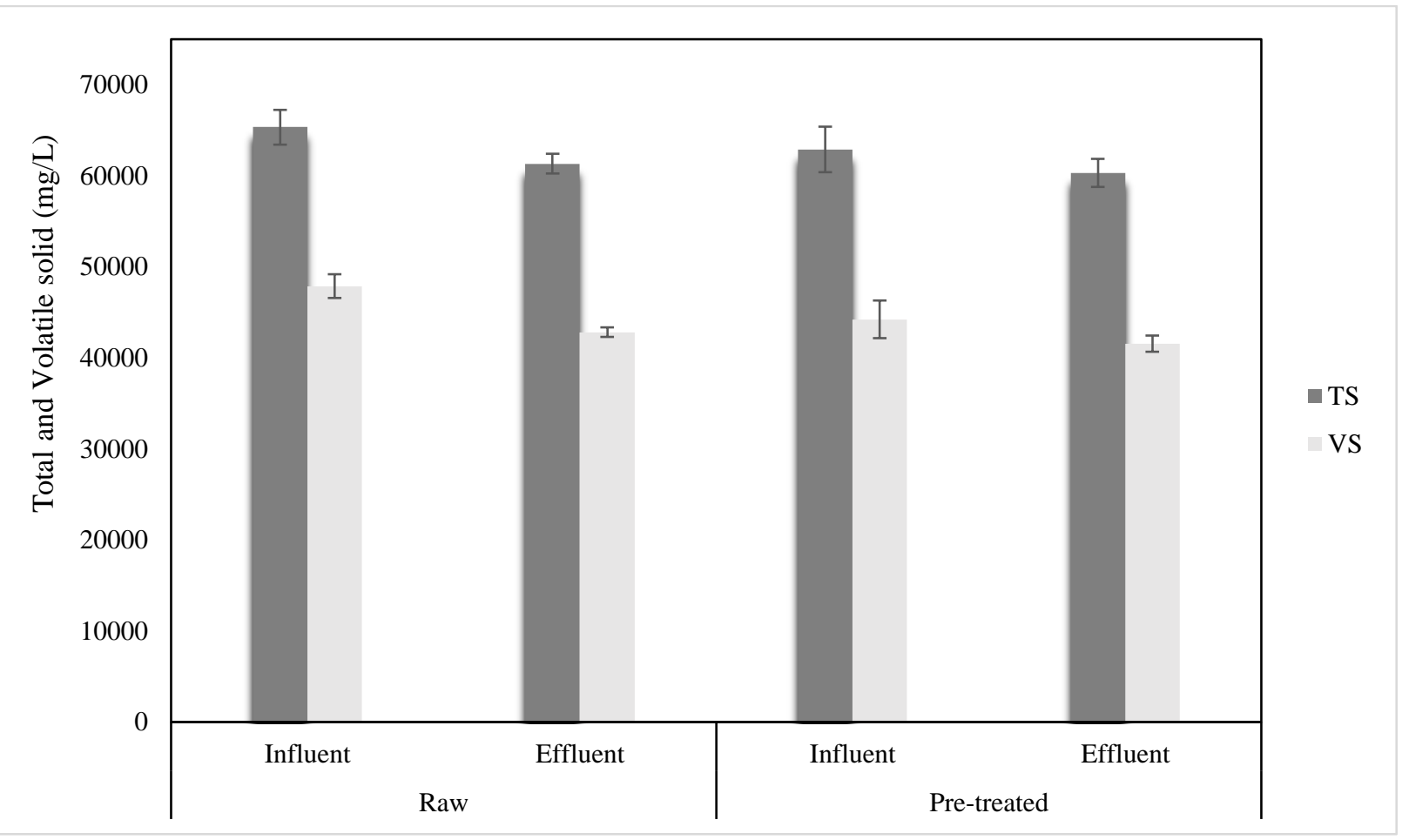

Figure 12 : Total \& volatile solid of raw \& pre-treated SSO

The TS value of raw and pre-treated sample shows almost the same value. The highest range of $65330 \mathrm{mg} / \mathrm{L}$ of TS is from the raw influent. The slight decrease in both raw effluent and pre-treated effluent sample value is due to the continuous mixing in the digester. The pre-treated sample is more soluble, so the value of TS for raw and pretreated samples observed decrease from $62896 \mathrm{mg} / \mathrm{L}$ to $60316 \mathrm{mg} / \mathrm{L}$ respectively.

For VS, it shows the same behaviour as of TS, but the highest value for VS is $47880 \mathrm{mg} / \mathrm{L}$ from the raw influent. Effluent in both the cases, i.e. raw and pre-treated observed slight decrease from its influent value. For raw sample, $47880 \mathrm{mg} / \mathrm{L}$ to $42823 \mathrm{mg} / \mathrm{L}$ and, pretreated $44231 \mathrm{mg} / \mathrm{L}$ to $41559 \mathrm{mg} / \mathrm{L}$. 
The average result of TSS and VSS which was done in triplicate of raw and pre-treated samples are dramatize in figure 13.

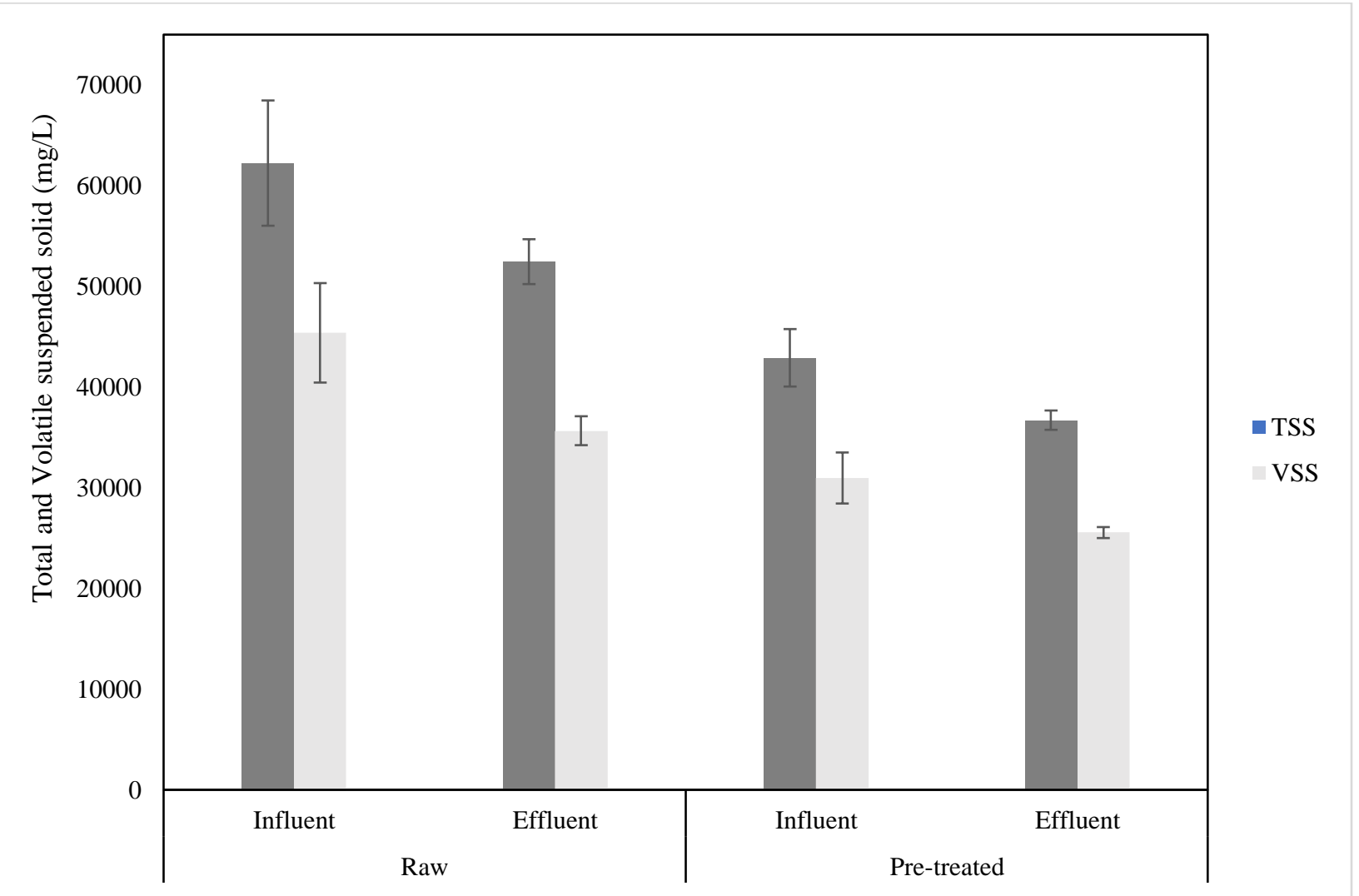

Figure 13: Total \& volatile suspended solid of raw \& pre-treated SSO

The figure 13 shows that the average value for TSS in raw influent is very high with a value of $62242 \mathrm{mg} / \mathrm{L}$ as comparative to all. Raw effluent observes a decrease in value to $52454 \mathrm{mg} / \mathrm{L}$ as the substrate was continuous mixing in the reactor with retention time for 3 days which make it more soluble. In the pretreated sample, the substrate was treated at a high temperature of $170^{\circ} \mathrm{C}$, so the value of TSS of the pretreated sample, influent with a value of $42904 \mathrm{mg} / \mathrm{L}$ reduces to the value of $36712 \mathrm{mg} / \mathrm{L}$ for effluent.

The average volatile suspended solids show the same behaviour as that of average total suspended solids. The value of raw influent $45383 \mathrm{mg} / \mathrm{L}$ decreased to a value of 35665 $\mathrm{mg} / \mathrm{L}$ in the raw effluent. In the pre-treated sample, the value of influent $30967 \mathrm{mg} / \mathrm{L}$ decrease to $25547 \mathrm{mg} / \mathrm{L}$ in the effluent. 
The average result of Total Chemical Oxygen Demand (TCOD) are presented in figure 14 for raw and pre-treated samples which was done in triplicate.

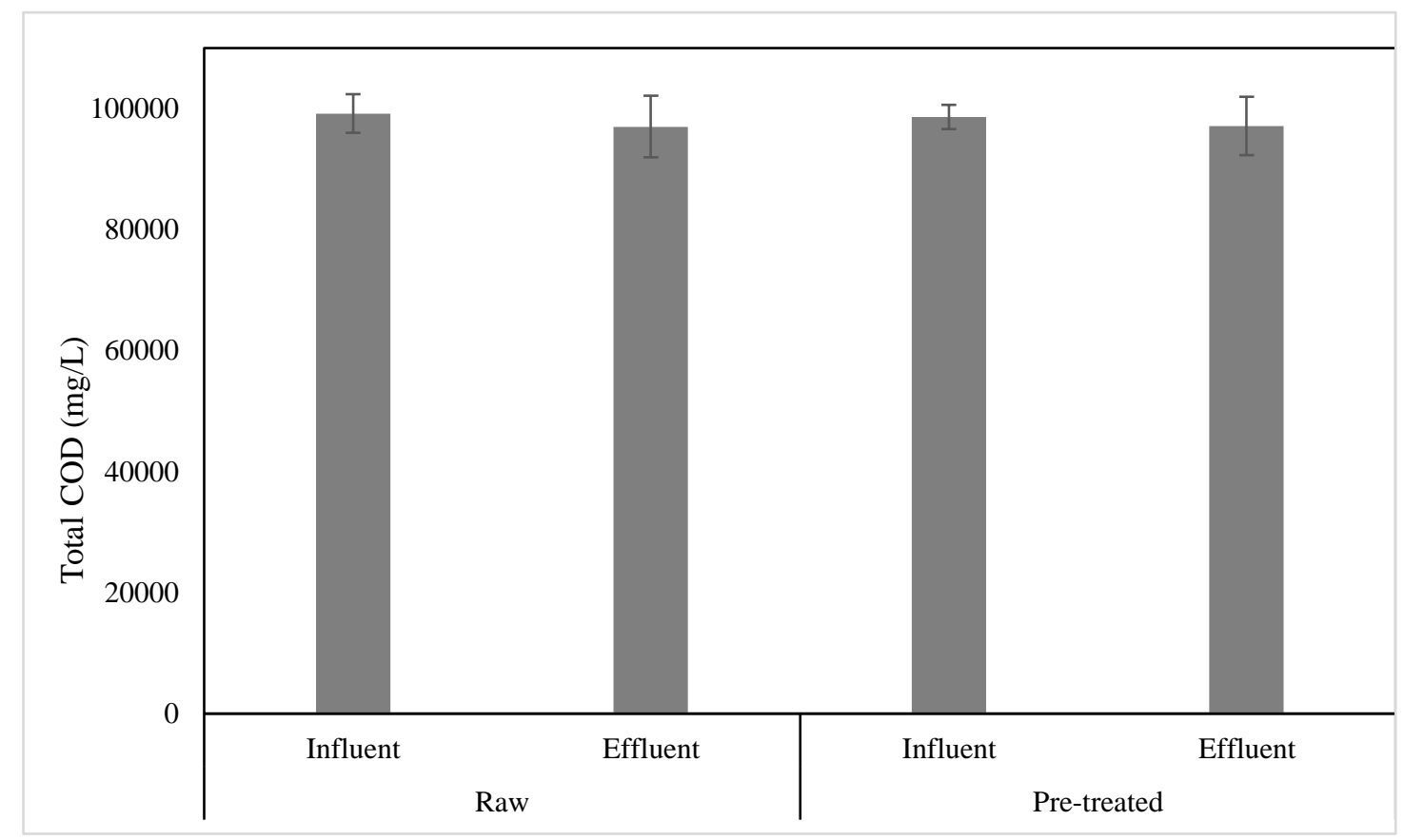

Figure 14: Total chemical oxygen demand of raw \& pre-treated SSO

The figure 14 shows that there is no big difference in the concentrations of the raw and pre-treated sample for both influent and effluent. For a raw sample, influent analysis with the value of $99183 \mathrm{mg} / \mathrm{L}$ reduced to effluent with a value of $97033 \mathrm{mg} / \mathrm{L}$. This little change also indicates that the fermentation process was preventing methanogenesis were methane production takes place.

For a pre-treated sample, the value of influent $98617 \mathrm{mg} / \mathrm{L}$ gives the effluent with a value of $97125 \mathrm{mg} / \mathrm{L}$. Total COD should be conserved in fermenters because the hydrolysis process only converts particulate COD into Soluble COD.

Figure 15 shows the average result for Soluble Chemical Oxygen Demand (SCOD) which was done in triplicate for raw and pre-treated samples. 


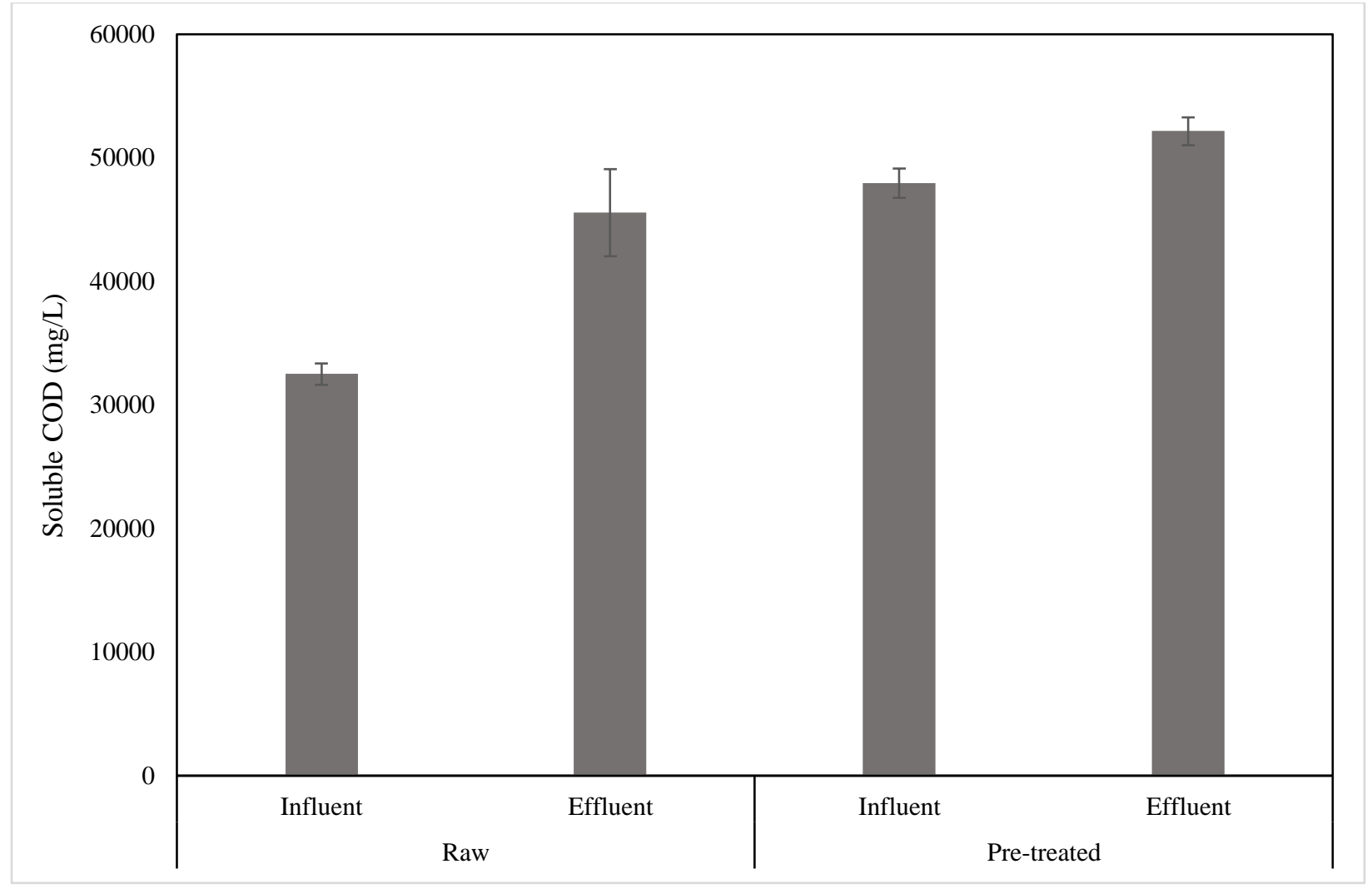

Figure 15: Soluble chemical oxygen demand of raw \& pretreated SSO

Figure 15 shows a significant increase in the raw sample for influent to effluent value. There is an increase from raw influent to pre-treated influent because the hydro-thermal process makes the substrate more soluble which increases its value. The value of raw influent $32498 \mathrm{mg} / \mathrm{L}$ rises to $45563 \mathrm{mg} / \mathrm{L}$ for raw effluent. This change is due to a small amount of methanogenic activity.

For a pre-treated sample, there was a slight increase in average value from influent to effluent; the value changes from $47950 \mathrm{mg} / \mathrm{L}$ to $52150 \mathrm{mg} / \mathrm{L}$ respectively. This is a good indication that there was minimal COD loss to methanogenesis.

Figure 16 shows the average result for Total Carbohydrates which was done in triplicate for raw and pre-treated samples. 


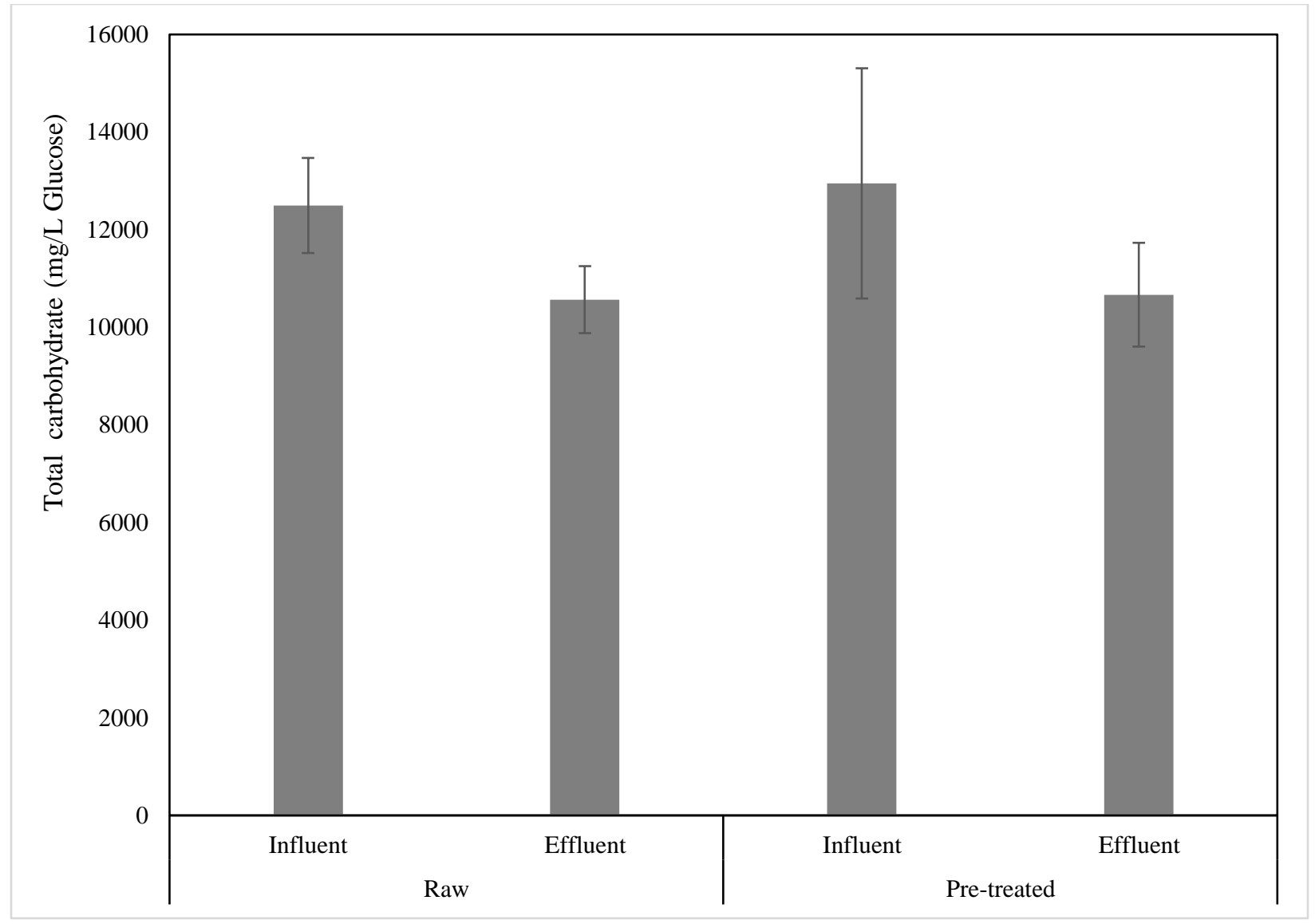

Figure 16: Total carbohydrates of raw \& pre-treated SSO

Figure 16 shows the average result for total carbohydrates for the raw and pre-treated sample. The concentration of total carbohydrates reduces in effluent which shows that there is the production of VFA.

In the raw sample, the value of influent $12496 \mathrm{mg} / \mathrm{L}$ reduces to10567 in the effluent.

In the pre-treated sample, the influent value of $12949 \mathrm{mg} / \mathrm{L}$ falls to the value of 10668 $\mathrm{mg} / \mathrm{L}$ in the effluent.

Figure 17 shows the average result for Soluble Carbohydrates which was done in triplicate for raw and pre-treated samples. 


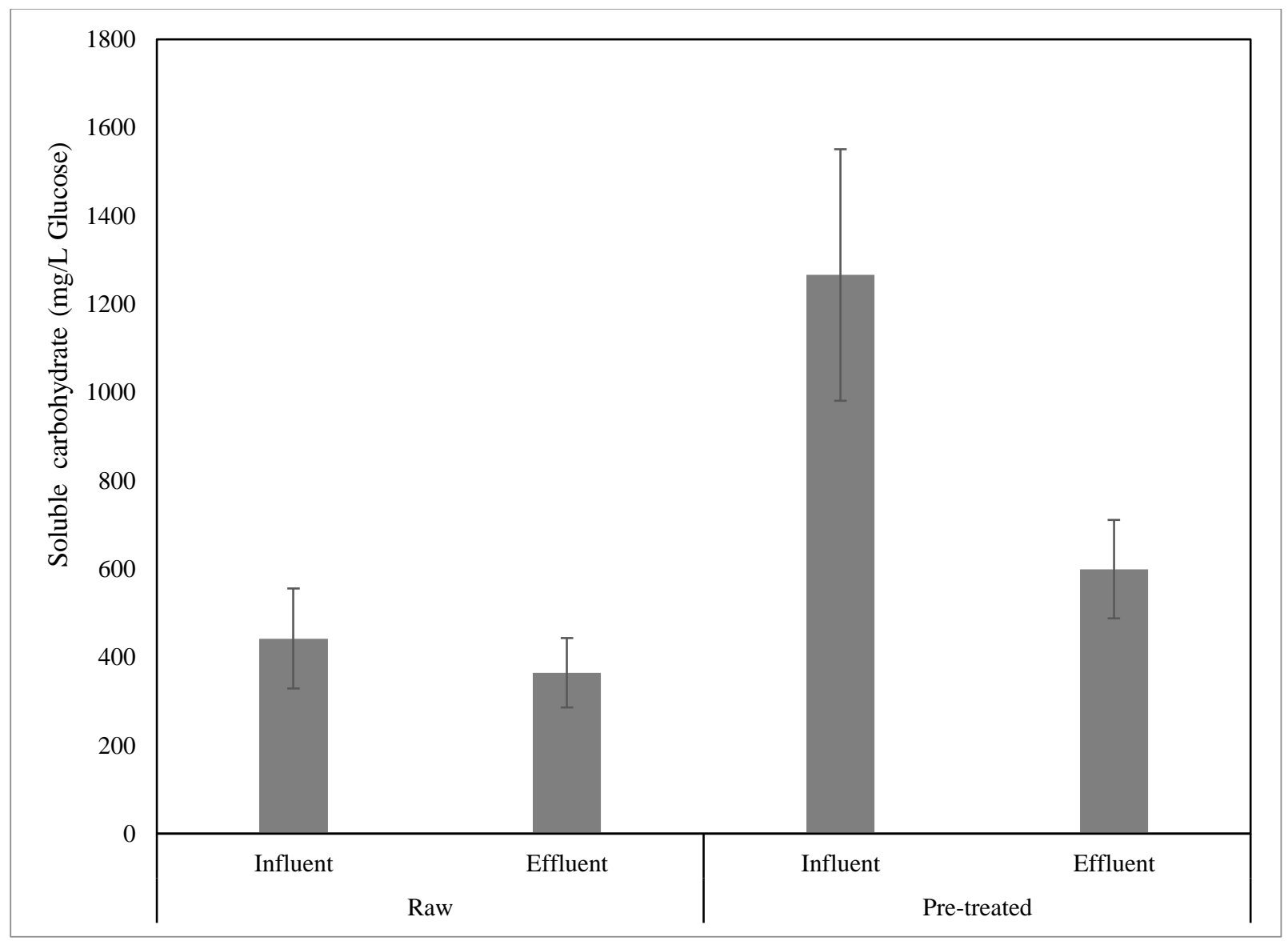

Figure 17: Soluble carbohydrates of raw \& pre-treated SSO

The figure clearly shows that in the pre-treated sample, there is a drastic decrease from influent to effluent because the hydro-thermal makes the substrate more soluble and carbohydrates are converted into VFA in large amount in the fermentation process. In the raw sample, there is not much change in average concentration from influent to effluent. In the pre-treated sample, the influent value of $1266 \mathrm{mg} / \mathrm{L}$ significantly reduces to 599 $\mathrm{mg} / \mathrm{L}$ because of VFA production.

Figure 18 shows the average result for alkalinity which was done in triplicate for raw and pre-treated samples. 


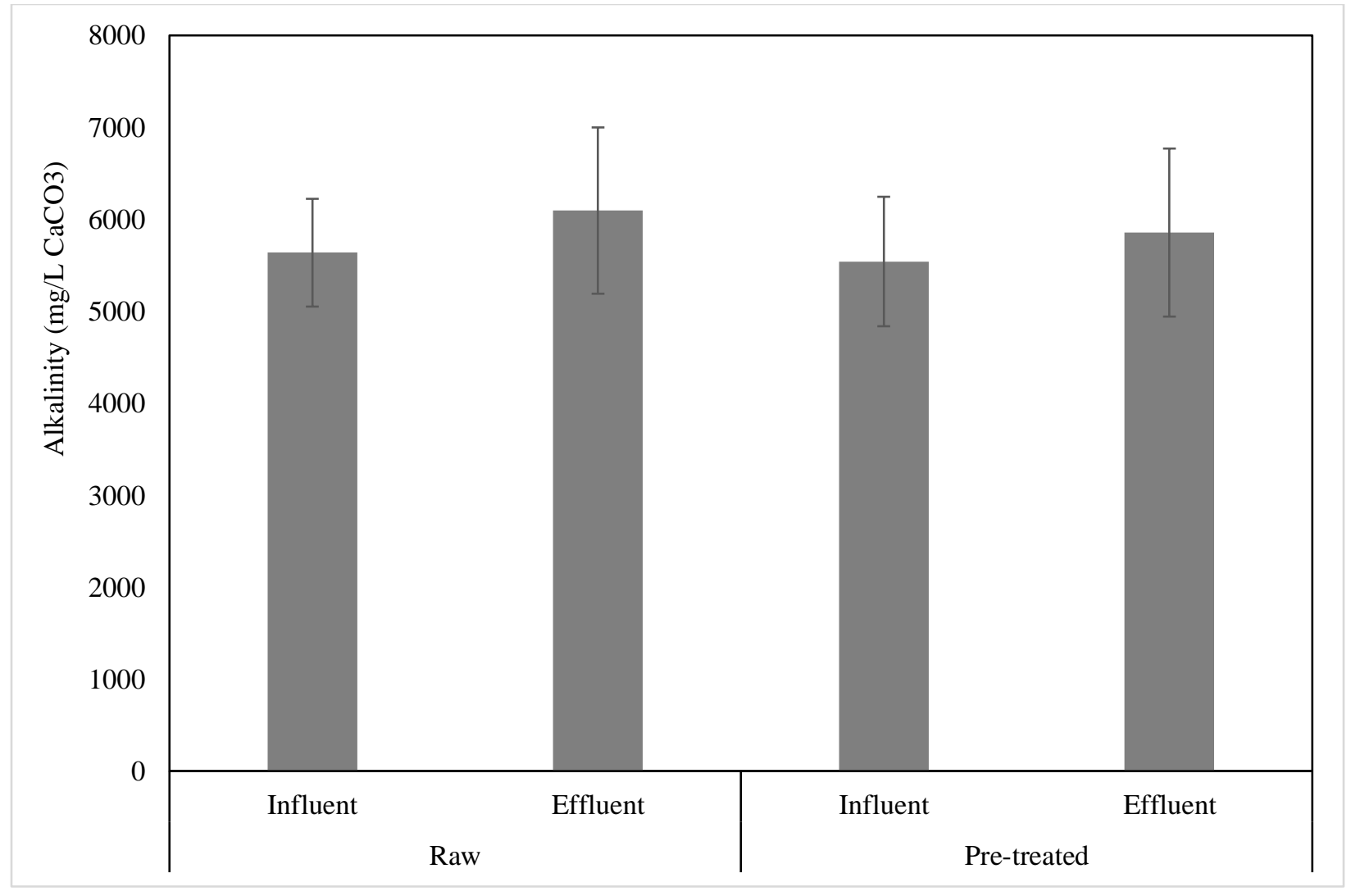

Figure 18: Alkalinity of raw \& pre-treated SSO

Alkalinity was very often used as a pointer of biological activity. Increase in Alkalinity means more biological processes. Figure 18 shows a slight increase in alkalinity concentration after fermentation proces. In the raw sample, a slight rise in influent to effleunt was observed with the value from $5637 \mathrm{mg} / \mathrm{L}$ to $6095 \mathrm{mg} / \mathrm{L}$. In the pre-treated sample, like raw sample, there was a slight increase in the value from influent to effleunt.

Figure 19 shows the average result of ammonia which was done in triplicate for raw and pre-treated samples 


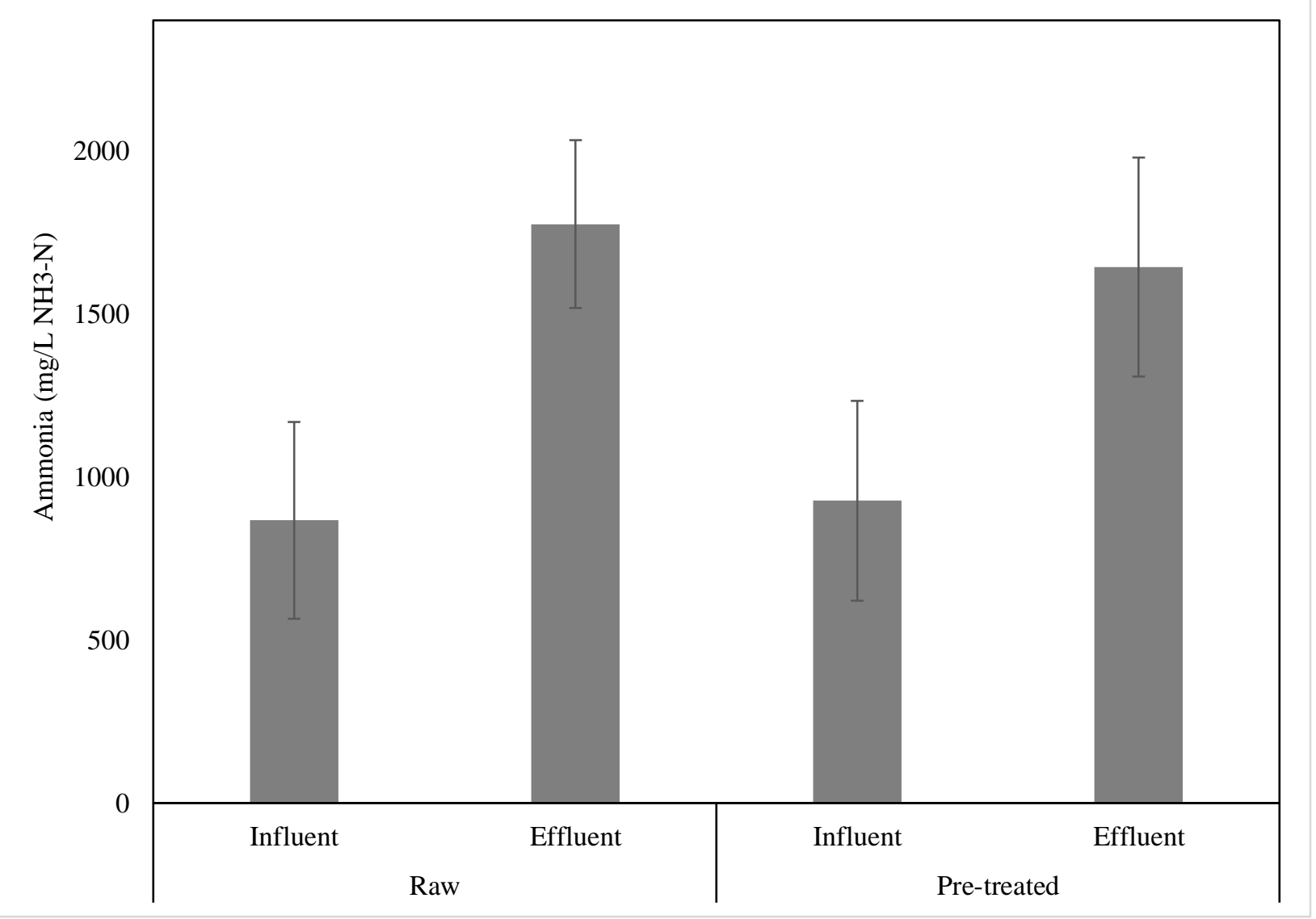

Figure 19: Ammonia of raw \& pre-treated SSO

Figure 19 demonstrate that average value for ammonia increased in the effluent for both raw and pre-treated sample. For a raw sample, an increase of influent from $867 \mathrm{mg} / \mathrm{L}$ to effluent $1775 \mathrm{mg} / \mathrm{L}$ was noted. For a pre-treated sample, the increase of influent from $927 \mathrm{mg} / \mathrm{L}$ to effluent $1644 \mathrm{mg} / \mathrm{L}$ was observed. The increase in the value of the ammonia also indicates that in the fermentation process, ammonia production is high.

Figure 20 shows the average result for Volatile Fatty Acids (VFA) which was done in triplicate for raw and pre-treated samples. 


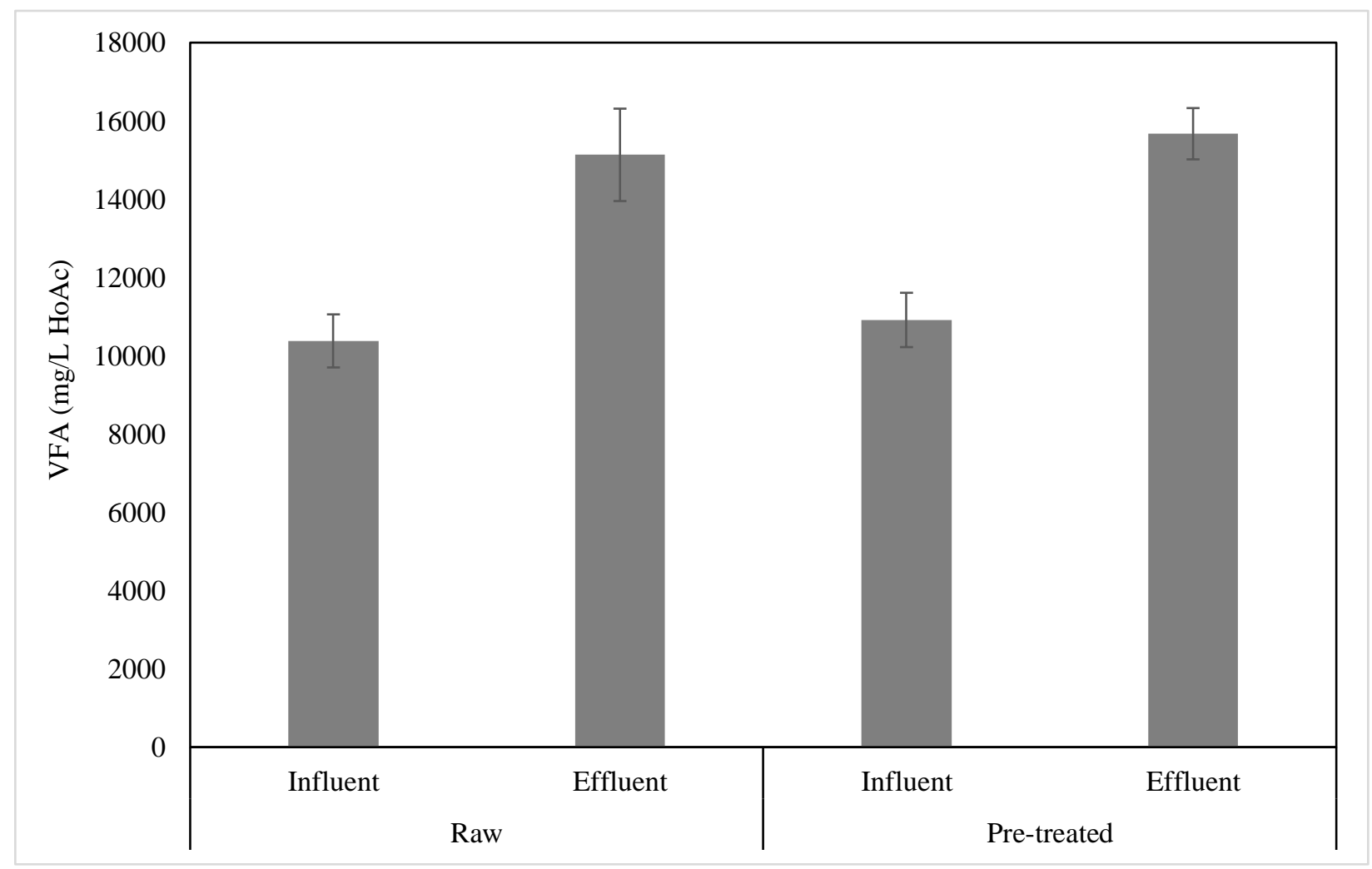

Figure 20: VFA of raw and Pre-treated SSO

Figure 20 shows the result of average volatile fatty acids in raw and hydro-thermalized or pre-treated sample. In the fermentation process, VFAs are produced and increase in the value of effluent marks this statement. Volatile fatty acids are the rich amount in SSO, but the fermentation process helps. High production of VFA was noted in pre-treated effluent with a value of $15672 \mathrm{mg} / \mathrm{L}$.

On an average, both raw and pre-treated sample produces almost the same VFA in the fermentation process. In the raw sample, the influent of $10379 \mathrm{mg} / \mathrm{L}$ rise to $15133 \mathrm{mg} / \mathrm{L}$ in effluent whereas in the pre-treated sample, the influent with $10914 \mathrm{mg} / \mathrm{L}$ increases to $15672 \mathrm{mg} / \mathrm{L}$.

Figure 21 shows the result for degree of solubilization in percentage for different processes. 


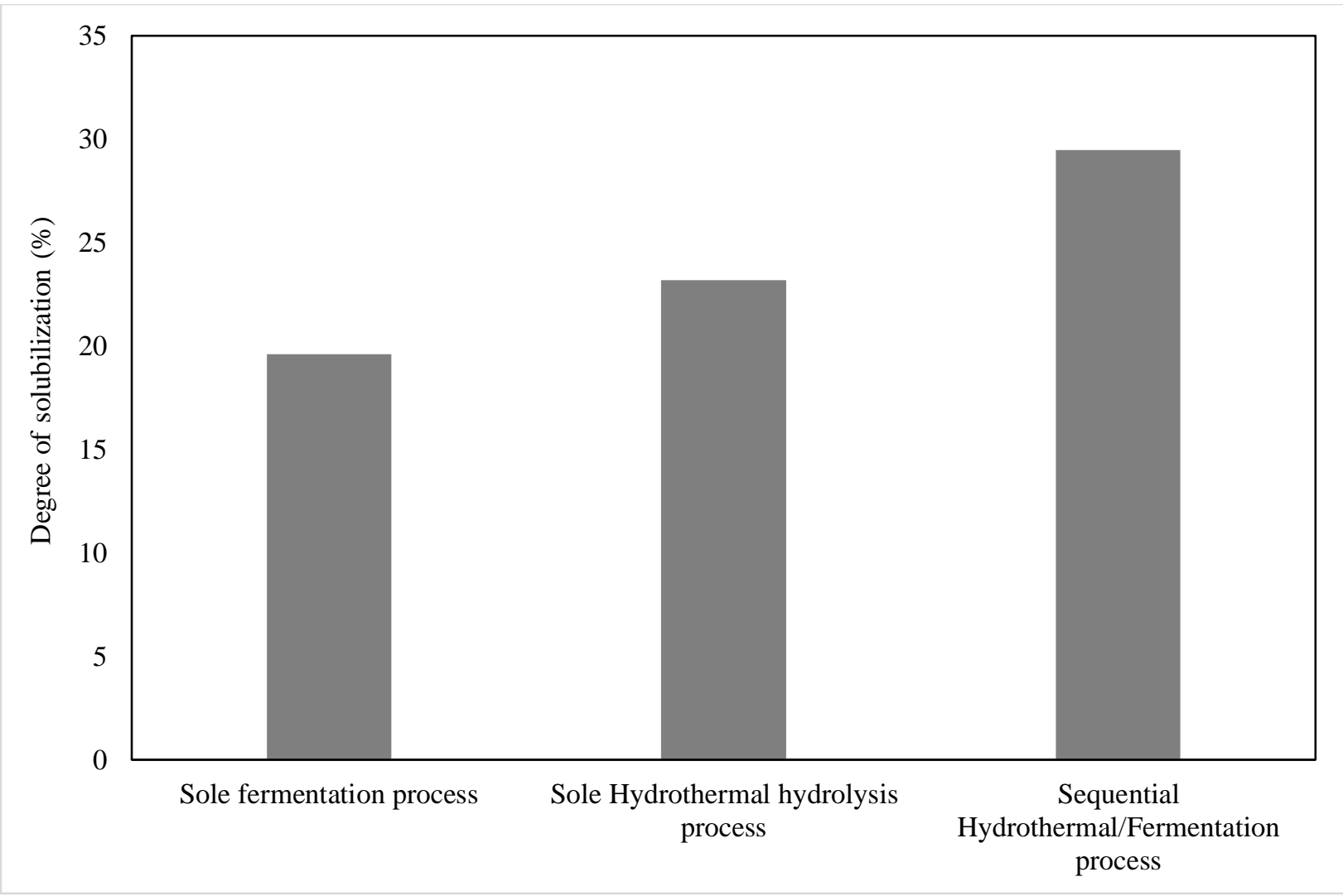

Figure 21: Degree of solubilization of SSO versus Percentage

The result indicate that COD mass balance conditions for hydrolysis and fermentation were favorable. The degree of solubilization of organic material yield more by sequential hydrothermal and fermentation process. The yield was calculated using the ratio of soluble COD and total COD as shown below.

$$
\operatorname{SCOD}(\text { yield })=\frac{\operatorname{SCOD}(\text { effluent })}{\operatorname{TCOD}(\text { influent })}
$$

Figure shows that degree of solubilization for sole fermentation is $20 \%$, where as in combined hydrothermal and fermentation process the degree of solubilization increased by $9 \%$ from fermentation process. On comparing, fermentation process versus hydrothermal process increases only $3 \%$ in hydrothermal process. 
Figure 22 shows the result for suspended solids reduction in percentage for different processes.

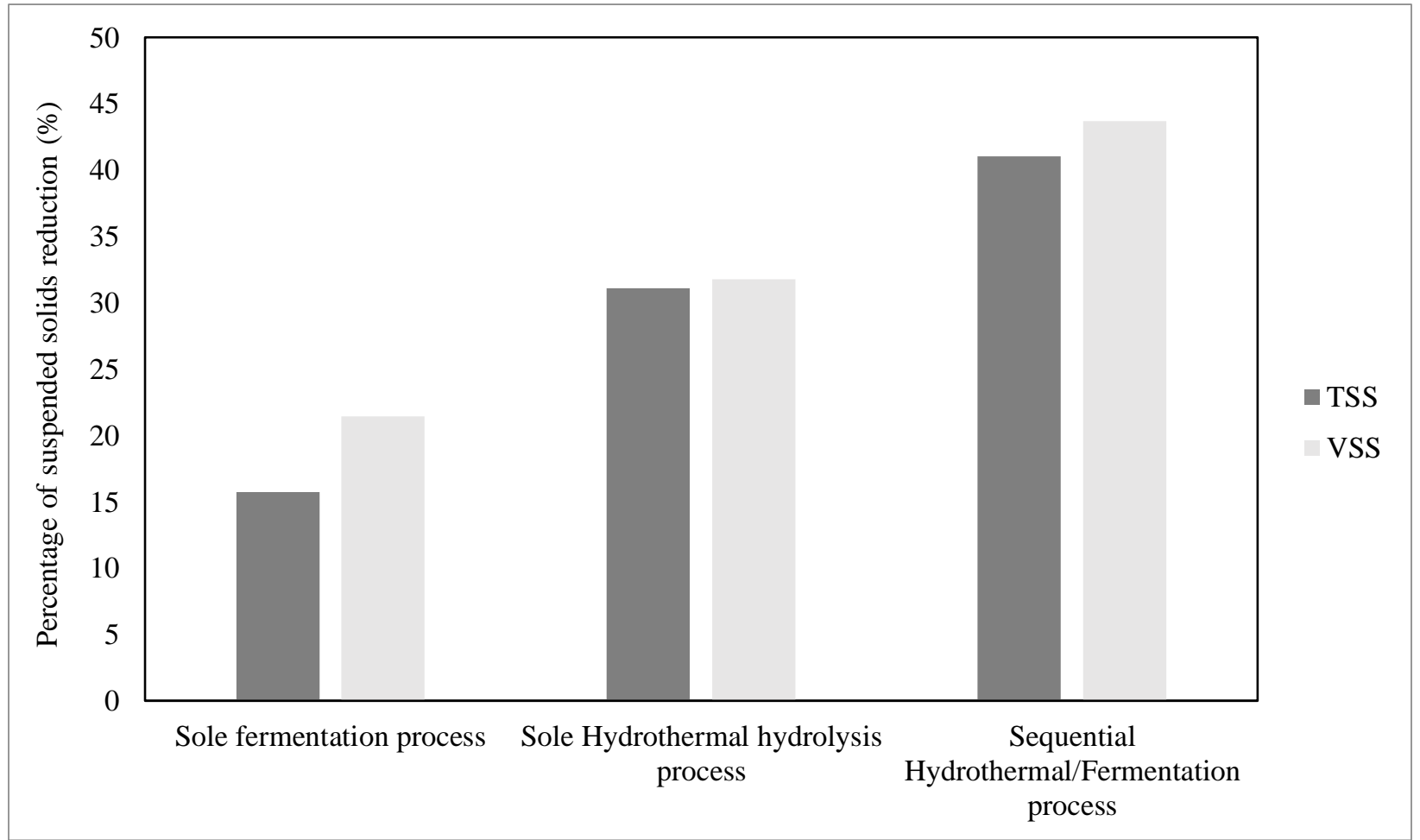

Figure 22: Fermentation process versus percentage of suspended solid reduction In this figure, reduction of suspended solids in TSS/VSS for three different processes namely sole fermentation process, sole hydrothermal process and combined hydrothermal and fermentation process is shown. It can be clearly depicted from the figure that combination of hydrothermal and fermentation process shows high reduction of suspended solids with $44 \%$ for TSS and $41 \%$ for VSS because of increase in solubilzation. The reduction of suspended solids in fermentation process for TSS and VSS are $16 \%$ and $21 \%$ respectively. In hydrothermal process, reduction of suspended solids increased as the substrate in more soluble after the hydrothermal treatment and, hence it shows suspended solids reduction by $31 \%$ for TSS and $32 \%$ for VSS. Also, the tedler bag connected to reactor did not observe evident production for methane gas. 


\section{CONCLUSION}

In this study, the production of volatile fatty acids from source separated organics for pretreated and raw sample is analyzed using semi-continuous reactor.

First, the results show that hydrothermal process increases the productivity of the VFAs. The VFA produced in the pre-treated sample were high from those of raw sample. Increase in almost $50 \%$ of VFA was noted from raw influent to pre-treated effluent. Second, the result for degree of solubilization was increased during hydrothermal and fermentation process, which also help to improve the production of VFA. Also, reduction of suspended solids was noticed to be increased significantly in hydrothermal and fermentation process. 


\section{References}

1. Adekunle, K. F. (2015). A Review of Biochemical Process of Anaerobic Digestion. Advances in Bioscience and Biotechnology, 205-212.

2. Albornoz, A. (2017). Characterization of acid phase anaerobic digestion of municipal sludges to improve biological nutrient removal processes ( Master Thesis ). Waterloo, Canada.

3. Appels, L. e. (2008). Principles and potential of the anaerobic digestion of wasteactivated sludge. Progress in Energy and Combustion Science.

4. Arudchelvam, Y. P. (May 2010). Predicting VFA formation by dark fermentation of particulate substrates. Bioresource Technology, 7492-7499.

5. Brylinsky, M. (2004). Manual for Prediction of Phoshphorus concentration. Nova scotia Department of Environment and labour .

6. Cardoso, V. e. (2014). Hydrogen Production by Dark Fermentation. Chemical Engineering Transactions, 481-486.

7. Chen, L. a. (June 2014). Anaerobic Digestion Basics. University of Idaho Extension, 1-6.

8. Chunlan Mao., Y. F. (May 2015). Review on research achievements of biogas from anaerobic digestion. Renewable and sustainable energy reviews, 540-555.

9. Fang, H. H. (2002). Effect of $\mathrm{pH}$ on hydrogen production from glucose by a mixed culture. Bioresource Technology, 87-93.

10. Gameiro, T. L. (October 2016). Hydrolytic-Acidogenic Fermentation of Organic Solid Waste for Volatile Fatty Acids Production at Different Solids Concentrations and Alkalinity Addition. Water, Air, and Soil Pollution, 227:391.

11. Jarvie, M. E. (2017). Anaerobic digestion.

12. Jing, Y. B. (2014). Effect of Increasing Total Solids Contents on Anaerobic Digestion of Food Waste under Mesophilic Conditions: Performance and Microbial Characteristics Analysis. PLos ONE .

13. Khan, M. A. (2016). Optimization of process parameters for production of volatile fatty acid, biohydrogen and methane from anaerobic digestion. Bioresource Technology, 738-748. 
14. Lee, D. J. (2015). Effect of Volatile Fatty Acid Concentration on Anaerobic Degradation Rate from Field Anaerobic Digestion Facilities Treating Food Waste Leachate in South Korea. Journal of Chemistry, 1-9.

15. Lee, W. S. (2014). A review of the production and applications of waste-derived volatile fatty acids. Chemcial Engineering Journal, 83-99.

16. Lilley, I. D. (1990). Acid fermentation of primary sludge at $20 \mathrm{C}$ (Master Thesis).

17. Lokshina, V. A. (1996). Modeling of volatile fatty acids degradation kinetics and evaluation of microorganism activity. Bioresource Technology, 69-80.

18. Manser, N. D. (January 2015). Effects of solids retentation time and feeding frequency on performance and pathogen fate in semi-continous mesophilic anaerobic digesters ( PhD:Dissertation ). Florida.

19. Mazeghrane, S. (2013). Modelling of dark fermentation from household organic waste based on modified ADM1. In: Proceedings of 13th World Congress on Anaerobic Digestion. Presented at 13. World Congress on Anaerobic Digestion, (p. 171 p.).

20. Monnet, F. (2003). An Introduction to Anaerobic Digestion of Organic Wastes. Carbon, 1-48.

21. Muzaffar Ahmad Mir., A. H. (Febraury 2016). Design considerations and operational performance of anaerobic digester: A review. Cogent Engineering.

22. Nayono, S. E. (2010). Anaerobic digestion of organic solid waste for energy production. PhD Proposal.

23. Neibling, L. C. (June 2014). Anaerobic Digestion Basics. University of Idaho Extension, 1-6.

24. Philip, D. L. (n.d.). Anaerobic Wastewater Treatment Processes. Indian Institute of Technology, Madras.

25. R. Hester, R. H. (2002). Environmental and Health Impact of Solid Waste Management Activities. Royal Society of chemistry.

26. Steffen, R., \& Szolar, O. a. (1998). Feedstocks for Anaerobic Digestion. 1-25.

27. Tania Gameiro., M. L. (September 2016). Hydrolytic-Acidogenic Fermentation of Organic Solid Waste for Volatile Fatty Acids Production at Different Solids Concentrations and Alkalinity Addition. Water, Air and soil pollution , 227:391. 
28. US Environmental Protection Agency. (2012, september). (U. E. Agency, Producer) Retrieved from https://cluin.org/download/Citizens/a_citizens_guide_to_pump_and_treat.pdf

29. USEPA. (2004). DR/3900 Spectrophotometer. HACH Company.

30. Verma, S. (2002). Biodegradable Organics in Municipal Solid Wastes. (Master's Thesis).

31. Wang, L. G. (n.d.). Geo engineer. Retrieved from geoengineer.org

32. Yang, Y. C. (15 December 2015). Kinetics and methane gas yields of selected C1 to C5 organic acids in anaerobic digestion. Water Research, 112-118.

33. Zhang, D. L. (2015). A review: factors affecting excess sludge anaerobic digestion for volatile fatty acids production. Water Science \& Technology, 678-88. 


\section{Glossary}

\begin{tabular}{|c|c|c|}
\hline$A D$ & - & Anaerobic Digestion \\
\hline ADM1 & & Anaerobic Digestion Model No 1 \\
\hline BOD & - & Biochemical Oxygen Demand \\
\hline $\mathrm{CHP}$ & - & Combined Heat and Power \\
\hline COD & - & Chemical Oxygen Demand \\
\hline HRT & - & Hydraulic Retention Time \\
\hline MSW & - & Municipal Solid Waste \\
\hline OLR & - & Organic Loading rate \\
\hline $\mathrm{pH}$ & - & power of Hydrogen \\
\hline PHA & - & Poly-Hydroxy-Alkanoates \\
\hline SCOD & - & Soluble Chemical Oxygen Demand \\
\hline SRT & - & Solid Retention Time \\
\hline SSO & - & Source Separated Organics \\
\hline TCOD & - & Total Chemical Oxygen Demand \\
\hline TS & - & Total solid \\
\hline TSS & - & Total Suspended Solid \\
\hline VFA & - & Volatile Fatty Acid \\
\hline VSS & - & Volatile Suspended Solid \\
\hline
\end{tabular}

